\title{
Magnetic mapping of fault zones in the Leka Ophiolite Complex, Norway
}

\section{Keywords:}

- Magnetic anomalies

- Ophiolite

- Serpentinization

- Fault

Received:

6. May 2019

Accepted:

7. January 2020

Published online:

25. June 2020

Electronic Supplement 1: Maps with data

Electronic Supplement 2: Regional background field

Electronic Supplement 3: NRM stereonets

\author{
Alexander Michels ${ }^{1}$, Christine Fichler ${ }^{1}$, Zeudia Pastore', Suzanne McEnroe ${ }^{1}$ \\ ${ }^{1}$ Department of Geoscience and Petroleum, Norwegian University of Science and Technology (NTNU), \\ 7491 Trondheim, Norway \\ E-mail corresponding author (Alexander Michels): Alexander.michels16@gmail.com
}

The island of Leka and surrounding skerries expose a complete suite of ophiolitic rocks, which are heavily faulted. Large areas consist of ultramafic rocks, which are locally hydrated and form serpentinites. Faults are commonly fluid pathways and can be areas of increased serpentinization. Because magnetite is a common product of serpentinization such fault zones add to the local magnetic response of the rocks. Here, ground-magnetic data were used in combination with aeromagnetic data to develop models over the major faults across the island. A mapping workflow was developed which uses tilted slabs to represent different zones of magnetization. The magnetic properties of surface-rock samples provided the constraints for the magnetic modeling. Sensitivity tests on the model showed the detection of magnetic fault zones to be limited to depths shallower than one $\mathrm{km}$. Magnetic modeling allowed for an estimation of the magnetization of several major faults. The magnetic zone of one of the largest faults, which forms the boundary between gabbro and ultramafic rocks, had an enhanced magnetization over a width of approximately 200 $\mathrm{m}$. The model is supported by both ground and aeromagnetic data: the first helped in refining the magnetization distribution at shallower depth, the latter allowed for modeling of the deeper part of the fault, indicating the geometry of a listric fault. The total magnetizations of the modeled slabs are well above the background magnetization of the Leka Ophiolite Complex (LOC) determined by modeling and on magnetic property data on $>500$ samples. This shift towards higher values indicates that serpentinization in some of the fault zones contributes significantly to the magnetic anomalies of the LOC.

\section{Introduction}

The ophiolite studied here is exposed on the island of Leka and the surrounding skerries, located in central Norway (Fig. 1). Ophiolites are fragments of oceanic crust and mantle, obducted onto continental margins commonly in association with an orogenic belt. The lithology of a complete ophiolite sequence consists of mantle peridotites, layered mafic-ultramafic rocks, gabbros, sheeted dikes, extrusive rocks, and sediments. Ophiolites are an important resource, for investigating surface and deep mechanisms involved in oceanic settings, and for exploration of precious and base metals that can occur in ultramafic rocks (Dilek \& Furnes, 2014).

(c) Copyright the authors. This work is licensed under a Creative Commons Attribution 4.0 International License.
Michels, A., Fichler, C., Pastore, Z. and McEnroe, S. 2020: Magnetic mapping of fault zones in the Leka Ophiolite Complex, Norway. Norwegian Journal of Geology 100, 202003. https://dx.doi.org/10.17850/njg100-1-1 

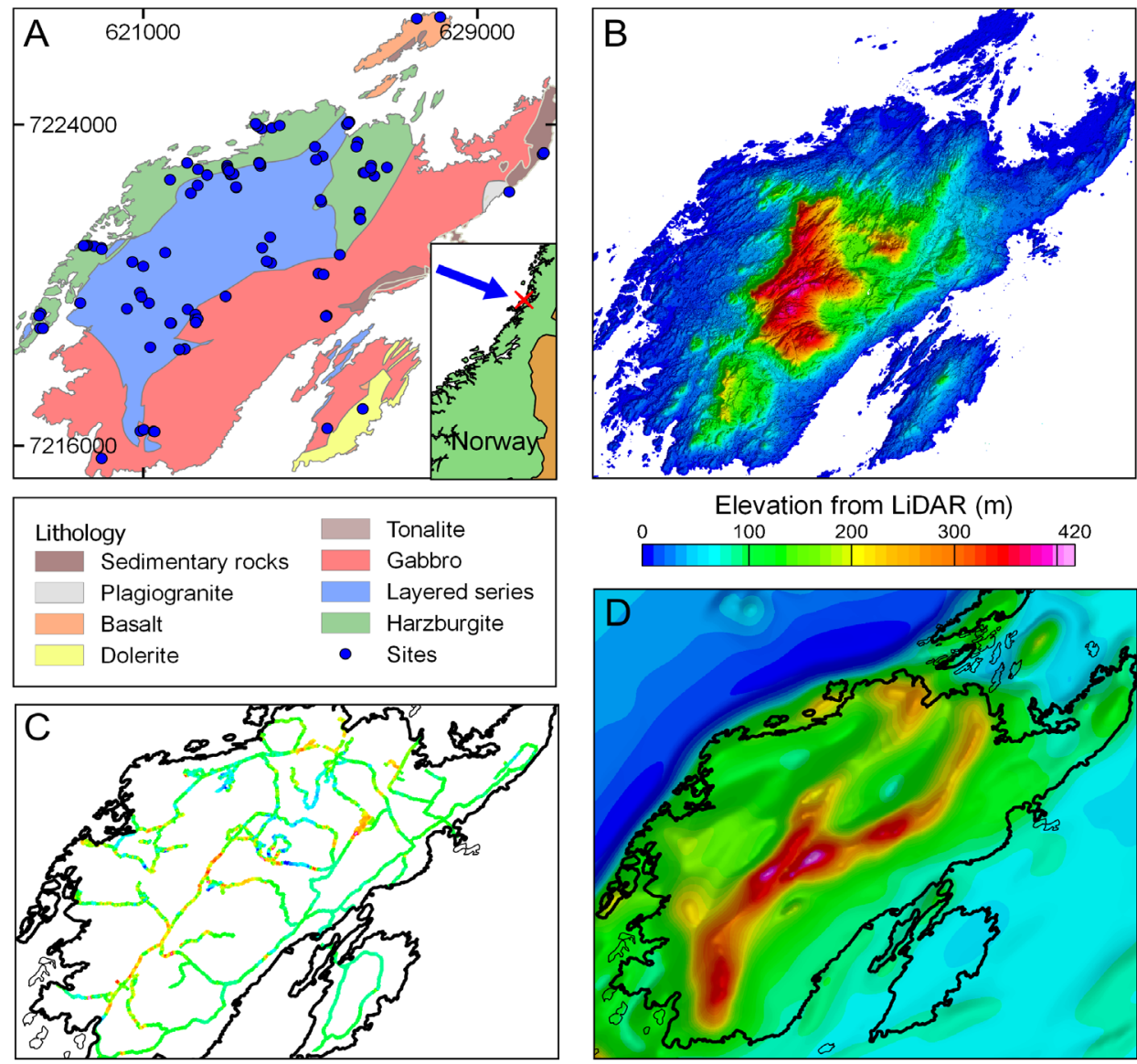

Ground magnetic anomaly (nT)

$\begin{array}{rrrr}-2000 \quad 0 & 2000 \quad 4000 \quad 6000\end{array}$
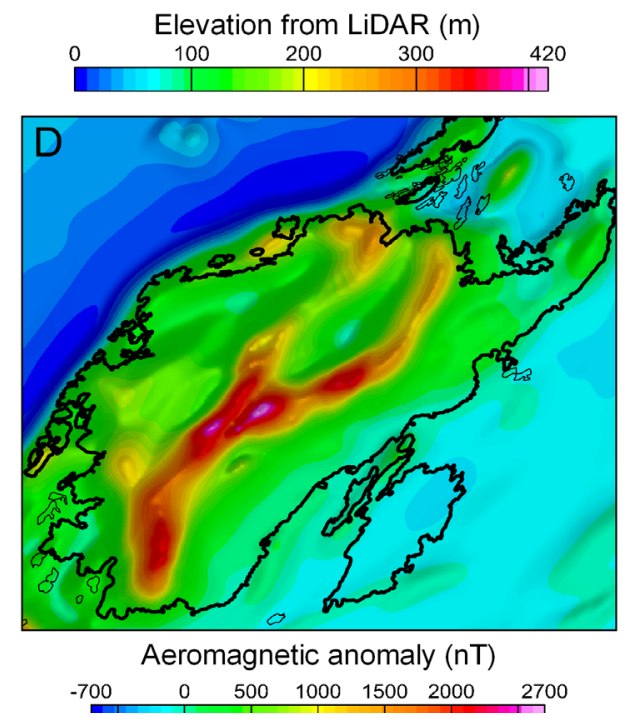

Figure 1. (A) Simplified geologic map of Leka based on Pedersen et al., 2011 (Geological Survey of Norway https:// www.ngu.no/en/topic/datasets) with locations where samples were taken. (B) LiDAR elevation data. (https://hoydedata.no/LaserInnsyn/). (C) Ground-magnetic data. (D) Aeromagnetic data (Olesen et al., 2015). Projection: UTM zone 32N, Datum: WGS84.

Here, we focus on faults in the mafic and ultramafic rocks in the Leka Ophiolite Complex (LOC). Faults are an important expression of tectonic processes because these reflect former stress regimes and can help to reconstruct the tectonic history (Nuriel et al., 2009). Fault zones accommodate fluid flow (cf., O'Hanley, 1991) leading to alteration of the faulted host rocks varying with chemistry, temperature and pressure (Barnes et al., 1972; Früh-Green et al., 2004; Nuriel et al., 2009). Of special interest here are the faults in ultramafic rocks, where fluids cause serpentinization. Settings where investigation focused on fault serpentinization include hyperextended margins (cf., Manatschal et al., 2000; Peron-Pinvidic \& Manatschal, 2009), and mid-oceanic ridge settings (cf., Smith et al., 2006; deMartin et al., 2007; Maffione et al., 2014), but little has been published on faults in relation to serpentinization in ophiolites (cf., Alexander \& Harper, 1992; Boschi et al., 2006; MacKenzie et al., 2006).

Serpentinization will affect the densities and magnetic properties. During serpentinization, olivine and pyroxenes are hydrated to form serpentine, brucite, and magnetite (Evans et al., 2013; Huang et al., 2017), leading to an increase in magnetization and a decrease in density (cf., Coleman \& Keith, 1971; Komor et al., 1985). The magnetic and gravity data can therefore be used to characterize areas of serpentinization. Gravity data were earlier used to model the subsurface of the LOC on a large scale (Sindre \& Pedersen, 1990; Titus et al., 2002), and more recently by Michels et al. (2018) who included new aeromagnetic data, and petrophysical properties from $>500$ samples. Here, we use ground 
magnetic data to target faults, and to investigate the variations in local magnetization near and in the fault areas. In ground-magnetic surveys, there is a smaller sensor elevation, which, combined with a high sampling rate, results in a higher resolution of the near-surface rock structure than can be obtained by aeromagnetic data. This is a consequence of the potential field character of magnetic data, where the increasing distance between source and sensor leads to a decrease in amplitude, and an enlargement of the wavelength (Blakely, 1995). An extensive collection of samples with measured densities and magnetic properties and recently released LiDAR data, with high-resolution elevation, was used, and provided constraints for the mapping and modeling of the magnetization in the LOC's fault zones.

The aims of this study are (1), to develop a workflow for mapping and modeling of magnetization in fault zones, (2), to apply this workflow to estimate the magnetization distribution across the faults of the LOC, and, (3), to relate this distribution to serpentinization, changes in lithology, and geometry of the fault zones.

\section{Leka geology}

The LOC is exposed on the island of Leka in Fig. 1. It is situated in the Uppermost Allochthon of the Norwegian Caledonides as part of the Helgeland Nappe Complex (Dunning \& Pedersen, 1988; Bucher-Nurminen, 1991; McArthur et al., 2014). According to Dunning and Pedersen (1988), the trondhjemite (plagiogranite, Fig. 1) that intruded into the upper gabbroic zone of the LOC yielded a U-Pb zircon age of $497 \pm 2$ Ma suggesting that the LOC may have formed during the Late Cambrian. The LOC formed as oceanic crust in a supra-subduction zone setting (Pearce et al., 1984; Furnes et al., 1988). A supra-subduction zone ophiolite is oceanic crust that formed in a backarc setting where the oceanic spreading zone is adjacent to an active oceanic subduction zone (Pearce et al., 1984).

All the components of an ophiolite are exposed in the LOC including the depleted upper mantle in the form of deformed harzburgite, crustal ultramafic cumulates, layered gabbros, basaltic dikes and pillow lavas (Prestvik, 1980; Furnes et al., 1988) (Fig. 1). The mantle material is predominantly harzburgite and is exposed mainly on the island's northwest shore, and between the layered series and the faulted contact with the gabbro. The mantle rocks are composed of olivine, primary and secondary clinopyroxene, Cr-spinel, ferritchromite, magnetite; serpentine, brucite and clinochlore (lyer et al., 2008). The latter formed by low-temperature alteration (lyer et al., 2008). The northeastern exposures of the harzburgite, have a primary contact to the west with the lower crustal cumulate peridotites (dunites and pyroxenites) representing the paleo-Mohorovicic discontinuity (paleo-Moho) and a fault contact to the east with the overlying gabbro. Around the petrological paleo-Moho, dunite lenses and sheets within the harzburgite can be observed (Albrektsen et al., 1991; Maaløe, 2005).

Stratigraphically above the paleo-Moho, are the crustal ultramafic cumulates, a sequence of layered websterite-wehrlite and dunite, here referred to as the 'layered series' following the nomenclature used by Furnes et al. (1988). The dunites in the layered series are primarily composed of olivine, serpentine, brucite, $\mathrm{Cr}$-spinel and magnetite. The wehrlites differ from these dunites and contain primary and secondary clinopyroxene, olivine, serpentine, brucite, clinochlore, $\mathrm{Cr}$-Al spinel, ferritchromite and magnetite (lyer et al., 2008).

The gabbroic texture ranges from fine to pegmatitic (Pedersen \& Furnes, 1991) and the rare earth element patterns of the gabbroic rocks are comparable to those from other gabbroic rocks in ophiolite complexes (Prestvik \& Roaldset, 1978). The gabbro is exposed to the south of the layered series. The contact of the gabbro with the layered series in the southwest contains alternating layers of gabbro and dunite. The eastern contact between the gabbro and the ultramafic rocks is mapped as a fault. 
The rocks of the LOC have experienced variable degrees of alteration. The basalts show evidence of greenschist-facies metamorphism (Prestvik, 1985; Furnes et al., 1988). Within the gabbro and mantle rocks, amphibolite-facies minerals have been reported (Prestvik, 1972, 1980; Furnes et al., 1988; Bucher-Nurminen, 1991). Variable degrees of serpentinization and chloritization are found within the ultramafic rocks (Austrheim \& Prestvik, 2008; Daae et al., 2013). Bucher-Nurminen (1991) reported an antigorite overprint of the ultramafic rocks likely occurred during obduction. During or after the obduction onto Laurentia ( $480 \mathrm{Ma}$ ) and in the Scandian orogeny, the LOC's mafic and ultramafic rocks underwent moderate-scale ductile deformation leading to folding and to the formation of an open syncline (Dunning \& Pedersen, 1988; Titus et al., 2002; Maaløe, 2005).

The major faults of the LOC strike NE-SW (Furnes et al., 1988; Titus et al., 2002; Pedersen et al., 2011). Titus et al. (2002) reported two distinct fault trends, described as brittle deformation occurring after folding of the LOC. The NE-SW-trending faults are longer than the NW-SE-trending faults (Titus et al., 2002). A recent gravity and magnetic model showed that the LOC's geometry could be modeled as a plunging synform (Michels et al., 2018), with a depth extent of $\sim 4 \mathrm{~km}$ below sea level. The main contact between the gabbro and the ultramafic rocks is a normal fault dipping towards the southeast. Most of the contacts between the geologic units were mapped as fault contacts (Furnes et al., 1988).
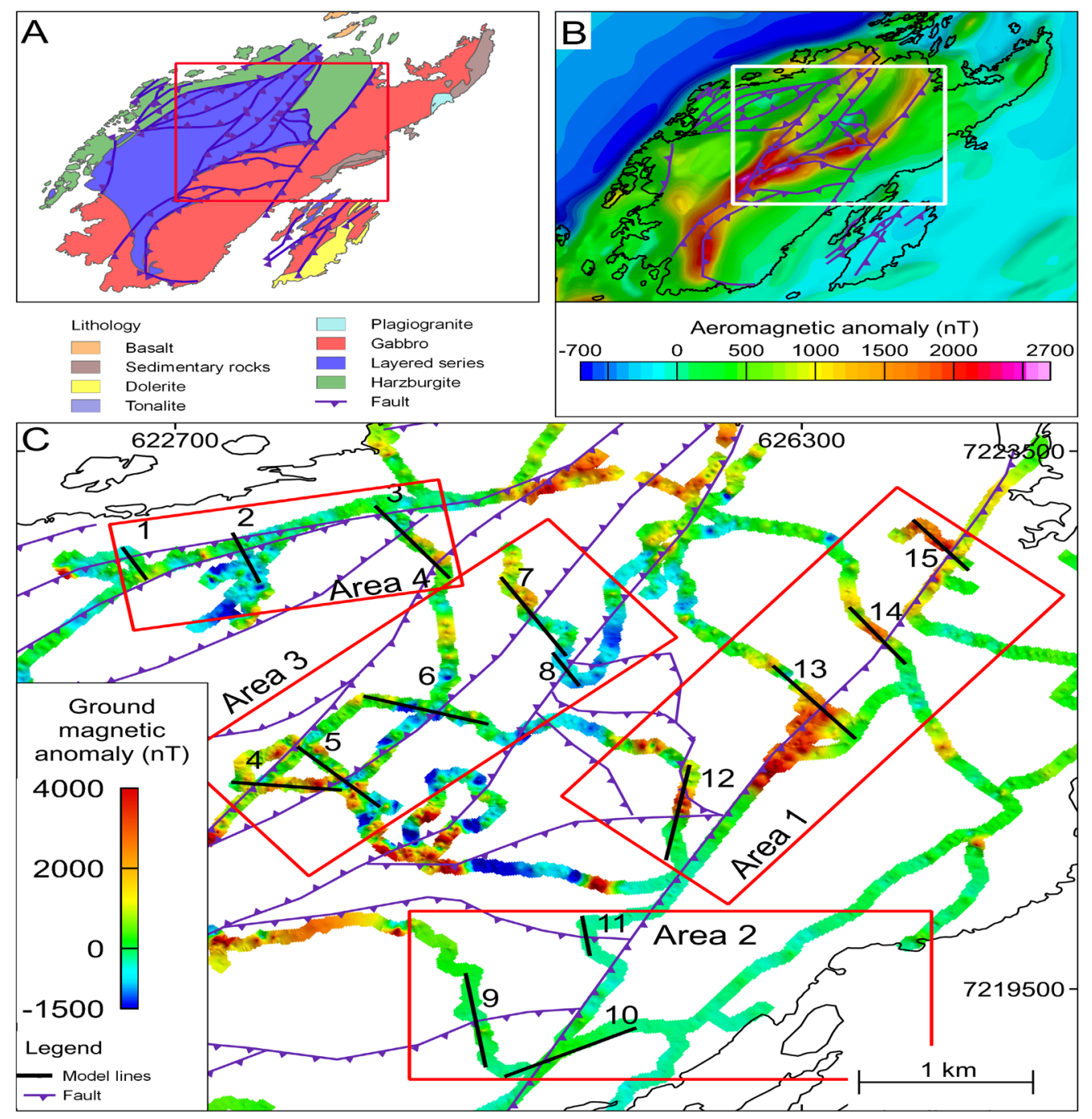

Figure 2. Fault locations (after Furnes et al., 1988; Titus et al., 2002) superimposed on: (A) geologic map (Pedersen et al., 2011; https://www.ngu.no/en/topic/datasets), (B) aeromagnetic data (Olesen et al., 2015), (C) ground-magnetic data, focus areas and modeled locations in red boxes. Projection: UTM zone 32N, Datum: WGS84. 
In Fig. 2, the faults from Furnes et al. (1988) are superimposed on both the geologic, the aeromagnetic (Olesen et al., 2015) and the ground-magnetic maps. There is a clear correlation between the aeromagnetic anomalies and the faulted contact between the gabbro and the ultramafic rocks. Michels et al. (2018) showed that the aeromagnetic anomaly is caused by both the contrast between the gabbro and the ultramafic rock, and by the higher magnetization in the fault zone (Fig. 2C, area 1). This fault is a focus area of the modeling presented below.

\section{Methods and data}

\section{Petrophysical and magnetic properties of rock samples}

Samples were taken from 108 sites across the LOC as oriented blocks or oriented cores. Samples were oriented with a magnetic compass that was corrected for the local declination of the magnetic field (3.2 ${ }^{\circ}$, IGRF 2010, 11th generation, Finlay, 2010). Samples were collected as oriented blocks or drilled in the field using a paleomagnetic rock coring drill, with a diameter of $2.54 \mathrm{~cm}$ and oriented in situ. Blocks were drilled in the NTNU lab with a similar drill diameter. Cores were then cut into specimens with a length of $2.2 \mathrm{~cm}$, to fit into the AGICO JR-6A spinner magnetometer for remanent magnetization measurements. Sun compass corrections for local deviations in the field were necessary for the stronger samples. New samples and site data were added to the dataset from Michels et al. (2018). The resulting site averages for density, magnetic susceptibility, and natural remanent magnetization (NRM) intensity and direction are given in Table 1.

The 42 layered series sites (302 samples) had NRM values ranging from. 0.01 to $34 \mathrm{~A} / \mathrm{m}$, with an average of $5.5 \mathrm{~A} / \mathrm{m}$. Their average susceptibility value is 0.042 (SI) with a range from 0.0004 to 0.2096 (SI). Samples from the harzburgite have lower NRMs, with an intensity range from $<0.1 \mathrm{~A} / \mathrm{m}$ to $18 \mathrm{~A} / \mathrm{m}$, with an outlier of $127 \mathrm{~A} / \mathrm{m}$, and an average of $2.3 \mathrm{~A} / \mathrm{m}$ from 283 specimens. For $90 \%$ of the harzburgite samples NRM intensities are $<4 \mathrm{~A} / \mathrm{m}$. The average susceptibility value is $0.0282(\mathrm{SI})$, with a range from 0.0003 to 0.0687 (SI). The gabbro samples have an average susceptibility of 0.0004 (SI) and NRM of $0.05 \mathrm{~A} / \mathrm{m}$. The NRM directions are scattered. The magnetic properties are very weak compared to a typical gabbro (Clark, 1999). Though the 55 gabbroic samples from 12 sites in the gabbro may not be a statistically representative sample set, the aeromagnetic data confirm the weak character of the gabbro body.

The sites with the highest density values in the layered series are richer in chromite and have lower susceptibility and NRM values (Michels et al., 2018). Excluding the chromite-rich samples, the average site density values combined with stronger magnetization indicate likely areas of serpentinization. The highest NRM values are in the south, adjacent to the fault, and in the north where the layered series becomes narrow. The average magnetic properties, based on a range of values for the different rock types and site localities, were used as constraints for modeling of the respective lithologies (Table 1).

Table 1. Site averaged properties for the LOC. $N$ is the number of sites. NRM intensity is the vector averaged NRM intensity. Dec and inc are the vector averaged declination and inclination of the NRM. Susc is the site averaged magnetic susceptibility.

\begin{tabular}{lcccccc}
\hline Rock type & $\mathrm{N}$ & Density $\left(\mathrm{kg} / \mathrm{m}^{3}\right)$ & NRM intensity $(\mathrm{A} / \mathrm{m})$ & $\mathrm{NRM} \mathrm{Dec}\left(^{\circ}\right)$ & $\mathrm{NRM} \operatorname{Inc}\left({ }^{\circ}\right)$ & Susc [SI] \\
\hline Harzburgite & 42 & $2788 \pm 98.6$ & 2.3 & 25.3 & 83 & 0.0282 \\
Layered series & 42 & $2913 \pm 223.7$ & 5.5 & 22.3 & 58.8 & 0.042 \\
Gabbro & 12 & 3038 & 0.05 & 14.8 & 66 & 0.0004 \\
\hline
\end{tabular}




\section{Magnetic data}

Ground-magnetic measurements were made with a Geometrics G-859 cesium vapor magnetometer with an integrated GPS with a sampling rate of five measurements per second. While surveying along roads, the magnetometer was paused around large metal objects (i.e., guardrails or cars), whereas noise from AC power lines was mainly removed with an internal filter integrated in the magnetometer. The ground-magnetic data (Figs. $1 C$ \& 2 C) were processed by removing spikes and erratic data including the eventual remaining high-frequency noise from power lines, as well as anthropogenic noise. Another error source relates to a loss of GPS or magnetometer signal due to a sudden change in orientation of the sensor which could be caused by walking across uneven ground. The data from the magnetic observatory in Rørvik, Norway, were checked daily for significant changes in the external field due to solar activity. These data indicated that our survey was acquired during a magnetically quite period.

The ground-magnetic data were corrected by removing the Earth's magnetic field using the IGRF database (IGRF, 2010 11th generation, Finlay et al., 2010). Data were then gridded using the Kriging grid method (Journel \& Huijbregts, 1978) with a $5 \times 5 \mathrm{~m}$ grid cell size and a limited search radius to avoid creating a grid with a large lateral extension around the ground-magnetic data acquisition pathways. Gridding and map display were made in software GEOSOFT Oasis Montaj.

The aeromagnetic data were collected by the Geological Survey of Norway (NGU) as part of the Crustal Onshore-Offshore Project (Olesen et al., 2015), (Figs.1D \& 2B). The survey was acquired with an average flying height of $60 \mathrm{~m}$ above the topography using 3 Geometrics $822 \mathrm{~A}$ magnetometers. The flight line spacing was approximately $250 \mathrm{~m}$ while tie line spacing was $2.5 \mathrm{~km}$.

\section{Elevation/LiDAR}

LiDAR elevation data from the Norwegian Mapping Authority (https://hoydedata.no/Laserlnnsyn/) were gridded with grid cell sizes of $1 \times 1 \mathrm{~m}$ and $5 \times 5 \mathrm{~m}$, for sensor height correction (see below) and map display (Fig. 1B), respectively. Shaded relief maps were made with a SE light direction in order to highlight linear features parallel to the major fault trend. These maps were used for the mapping of lineaments.

\section{Modeling of the magnetization in fault zones}

This section addresses the development of a magnetic modeling approach with the aim to characterize the magnetization in fault zones. We take advantage of using both aeromagnetic and ground magnetic data. The ground magnetometer and aeromagnetic sensors are $2 \mathrm{~m}$ and $60 \mathrm{~m}$ above ground, respectively. The difference in acquisition height has a major impact on the magnetic anomaly pattern.

The field's amplitude caused by a magnetic source will decay with a $1 /$ depth $^{N}$ relation, where depth is the vertical distance between source and acquisition level and $\mathrm{N}$ is the structural index of the source. $\mathrm{N}$ has different values dependent on the geometry of the source body: point sources $(\mathrm{N}=3)$, horizontal line sources $(N=2)$ and thin horizontal and vertical sheets $(N=1)$. Furthermore, the wavelength of magnetic anomalies increases with increasing depth to its sources (cf., Hinze et al., 2013). Consequently, the ground-magnetic anomalies with their short distance to the source will exhibit a high amplitude-short wavelength pattern, whereas the aeromagnetic anomalies will show lower amplitudes and larger wavelength. Aeromagnetic anomalies will also emphasize sources with low structural index.

Ground-magnetic data form the central dataset for the modeling workflow. It is expected that these data will show subtle anomalies that are not visible on aeromagnetic data. However, the latter is used to 
extend the shallow fault model towards greater depth or into the map plane, where no groundmagnetic data exist. The following section describes the choice of modeling style, the prerequisites for the modeling, sensitivity analyses, and the workflow, used to model magnetization in fault zones.

\section{Modeling styles}

The magnetic anomaly was calculated with the modeling program (GEOSOFT GMSYS2D), which allows interactive modification of susceptibility and NRM intensity, declination and inclination of source bodies. Inversion in this program is only possible for the susceptibility. Therefore, the vectoraveraged NRM intensity and directions were used for the respective rock units. This procedure leads to a dependence between the inverted susceptibilities and the predefined NRM values, which can be mitigated with rock constraints on the NRM, but not fully avoided. To suppress this problem, we calculated the total magnetization $\left(\vec{J}_{t}\right)$ (Eq. 1 ) and used this in the geological interpretation. The total magnetization is calculated by adding the average NRM $\left(\vec{J}_{r}\right)$ and the Induced magnetization $\left(\vec{J}_{i}\right)$. The latter is calculated as the product of the average susceptibility $(k)$ and of the local Earth's vector magnetic field strength $(\vec{H})$ derived from the International geomagnetic reference field (IGRF, $201011^{\text {th }}$ generation, Finlay et al., 2010).

$$
\vec{J}_{t}=\vec{J}_{r}+\vec{H} * k \quad \text { or } \quad \vec{J}_{t}=\vec{J}_{r}+\vec{J}_{i}
$$

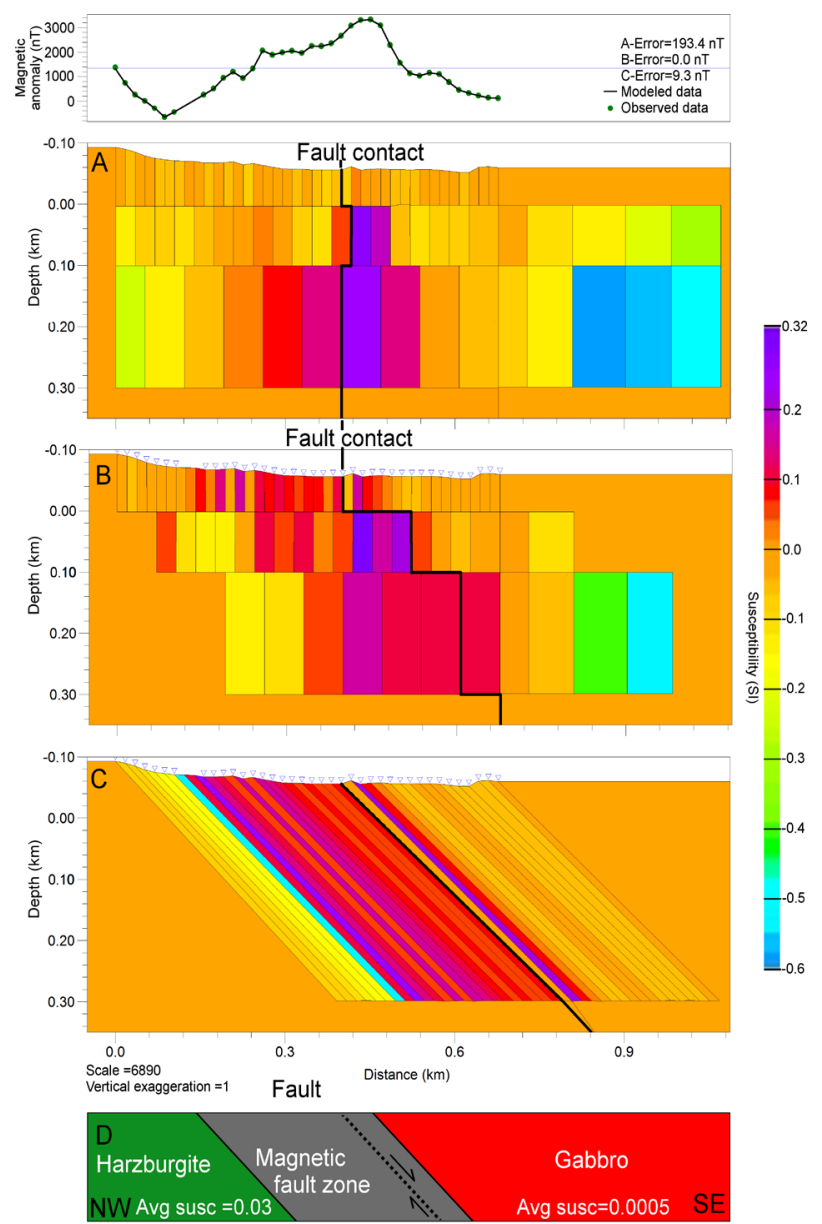

Figure 3. Unconstrained inversion result for susceptibilities; black line shows the location where the NRM value changes according to the lithology (D); see text for details. (Top) Observed and modeled ground magnetic data along profile 13 (see Fig. 2C for location). (A) Block model with vertical fault contact. (B) Block model shaped according to the dip of the fault. (C) Slab model shaped according to the dip of the fault. (D) Lithology sketch of the fault zone (C). 
Table 2. Comparison of slab model and block model

\begin{tabular}{|c|c|c|}
\hline & Block model & Slab model \\
\hline \multirow{3}{*}{$\begin{array}{l}\text { Geometry of } \\
\text { magnetic fault fill }\end{array}$} & $\begin{array}{l}\text { The dip is represented by } \\
\text { property changes }\end{array}$ & $\begin{array}{l}\text { The dip is represented by } \\
\text { slab angle }\end{array}$ \\
\hline & Multiple faults and dips & One dip \\
\hline & $\begin{array}{l}\text { Property variation with } \\
\text { depth }\end{array}$ & $\begin{array}{l}\text { No property variation along } \\
\text { single slabs }\end{array}$ \\
\hline Approximation of dip & Coarse & Precise \\
\hline Ambiguity of inversion & $\begin{array}{l}\text { Larger solution space depen- } \\
\text { dent on start model }\end{array}$ & $\begin{array}{l}\text { Smaller solution space } \\
\text { dependent on start model }\end{array}$ \\
\hline \multirow[b]{2}{*}{ Inversion } & Larger number of blocks & Smaller number of slabs \\
\hline & May give unrealistic models & $\begin{array}{l}\text { Simplified near realistic } \\
\text { model }\end{array}$ \\
\hline \multirow{3}{*}{$\begin{array}{l}\text { Application for } \\
\text { fault screening }\end{array}$} & $\begin{array}{l}\text { Requires intensive work to } \\
\text { get reliable results }\end{array}$ & Fast \\
\hline & Sensitive to starting model & $\begin{array}{l}\text { Less sensitive to starting } \\
\text { model }\end{array}$ \\
\hline & Difficult to compare results & Easy to compare results \\
\hline
\end{tabular}
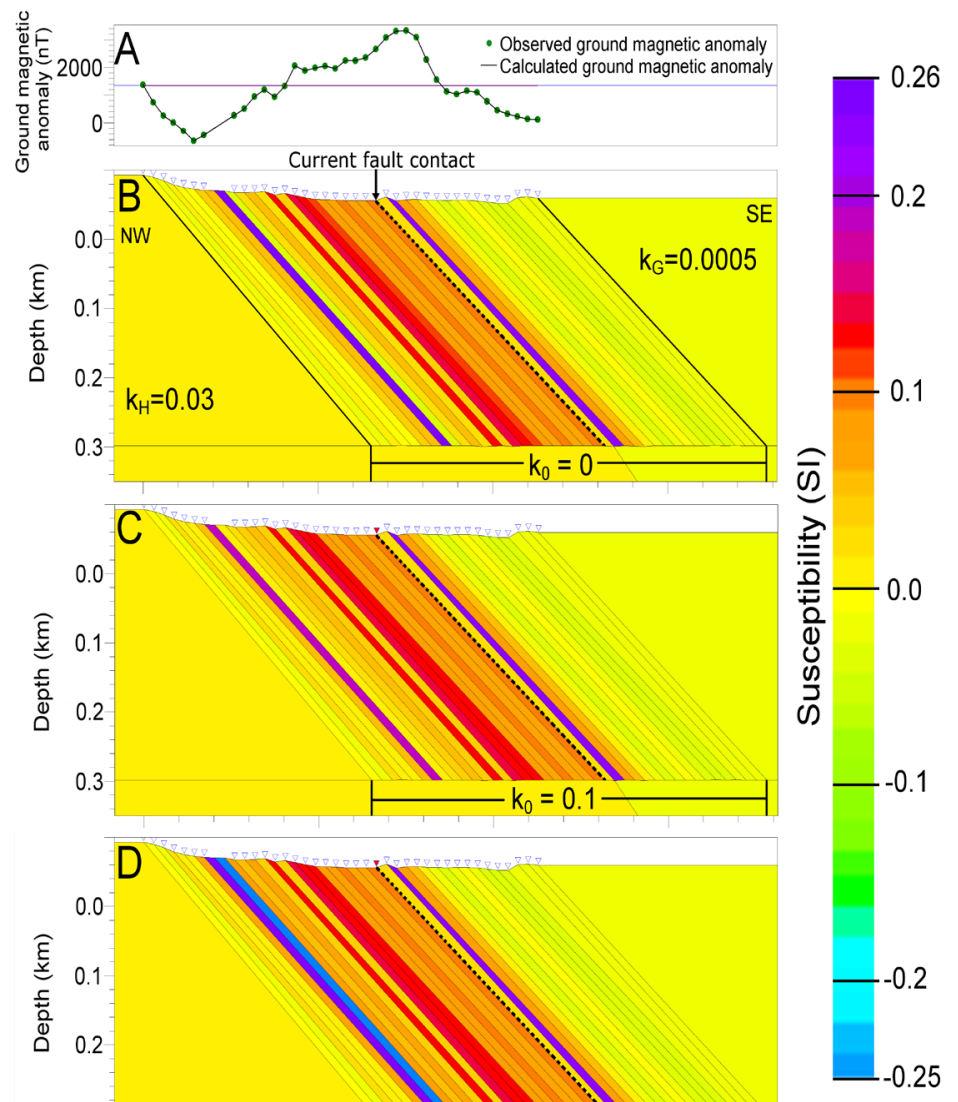

Figure 4. (Top) Observed and modeled ground-magnetic data along model line 13 (see Fig. 2C for location). Results of susceptibility inversion using different starting values $\left(k_{0}\right)$ in SI units for the slabs (see Fig. 3D for lithology); The dip of the fault contact is $45^{\circ}$ towards the southeast. For details see text. $k_{H}=$ average susceptibility value for harzburgite is 0.03 . $k_{G}=$ average susceptibility value for gabbro is 0.0005 . 
Fig. 3 presents different modeling styles for the shallow parts of a fault zone, with two different block models and a slab model. For all models, it is assumed that a fault is a 2D feature, i.e., infinitely extending perpendicular to the profile plane. This model is valid for faults, where its strike length is much greater than its vertical fault extension. In the case where the angle between the ground-magnetic traverse and the strike trend of the fault differs from 90 degrees, the deviation of the modeled anomalies was corrected as described below.

The models in Fig. 3A, 3B display rectangular blocks in the profile plane. Because the potential field resolution capability decreases with depth, these models consist of blocks of different size with the smallest blocks near to the surface. The start model in Fig. 3A was populated with the vector mean NRM properties (Table 1) of the harzburgites and the gabbros, divided by a vertical fault contact. The magnetic susceptibility was set to zero in all blocks. Subsequently, an unconstrained inversion was run for the susceptibility of the blocks. The result of the inversion is displayed in Fig. $3 \mathrm{~A}$ and did not mimic a fault geometry. The fault, based on previous modeling of aeromagnetic data (Michels et al., 2018) and structural contouring, is expected to dip towards ESE.

The start model in Fig. 3B incorporated a fault dip of approximately $\sim 45^{\circ}$ towards ESE, followed by running an inversion for the susceptibility; the result is shown in Fig. $3 \mathrm{~B}$. Both models result in blocks with large negative susceptibilities which are geologically unreasonable. Therefore, they need to be manually corrected to positive susceptibilities and subsequently require a change in the NRM values.

The slab model describes the magnetization in fault zones by a series of parallel slabs, each with constant magnetic attributes and having the same strike and dip as the fault (Fig. 3C). All slabs are terminated at the same depth. This simple model structure honors the strike and dip of the fault zone but does not allow for changes in magnetization with increasing depth. This assumes that magnetization changes occur in parallel with the fault plane with the same degree of serpentinization.

Before inversion, the slabs were assigned average site NRM properties and susceptibility was set to zero. The inversion result (Fig. $3 \mathrm{C}$ ) shows that the highest susceptibilities are near to the fault plane, and only a few slabs have negative susceptibilities that would require correction. Table 2 summarizes the advantages and disadvantages of the block versus the slab modeling methods.

The sensitivity of the susceptibility inversion to the choice of the starting values is documented in Fig. 4. Here, different starting values were chosen, within the range of the measured susceptibilities. To make the inversion results comparable, the starting NRM values were set to the mean values based on lithology (Table 1 and Electronic Supplement 1). The results of the inversion are not unique but show a high similarity.

\section{Workflow}

The workflow, used to extract information about the fault zones, explains the use of the data, the development of the model and the interpretation (Fig. 5). Steps A-G are explained in the following sections.

\section{Data input}

[Step A] Known or suspected fault locations from published sources (papers, geologic maps, or other surveys) with their structural attributes (strike and dip) must be georeferenced and superimposed on the ground-magnetic data. In older maps with fault locations they may not match recent topography 


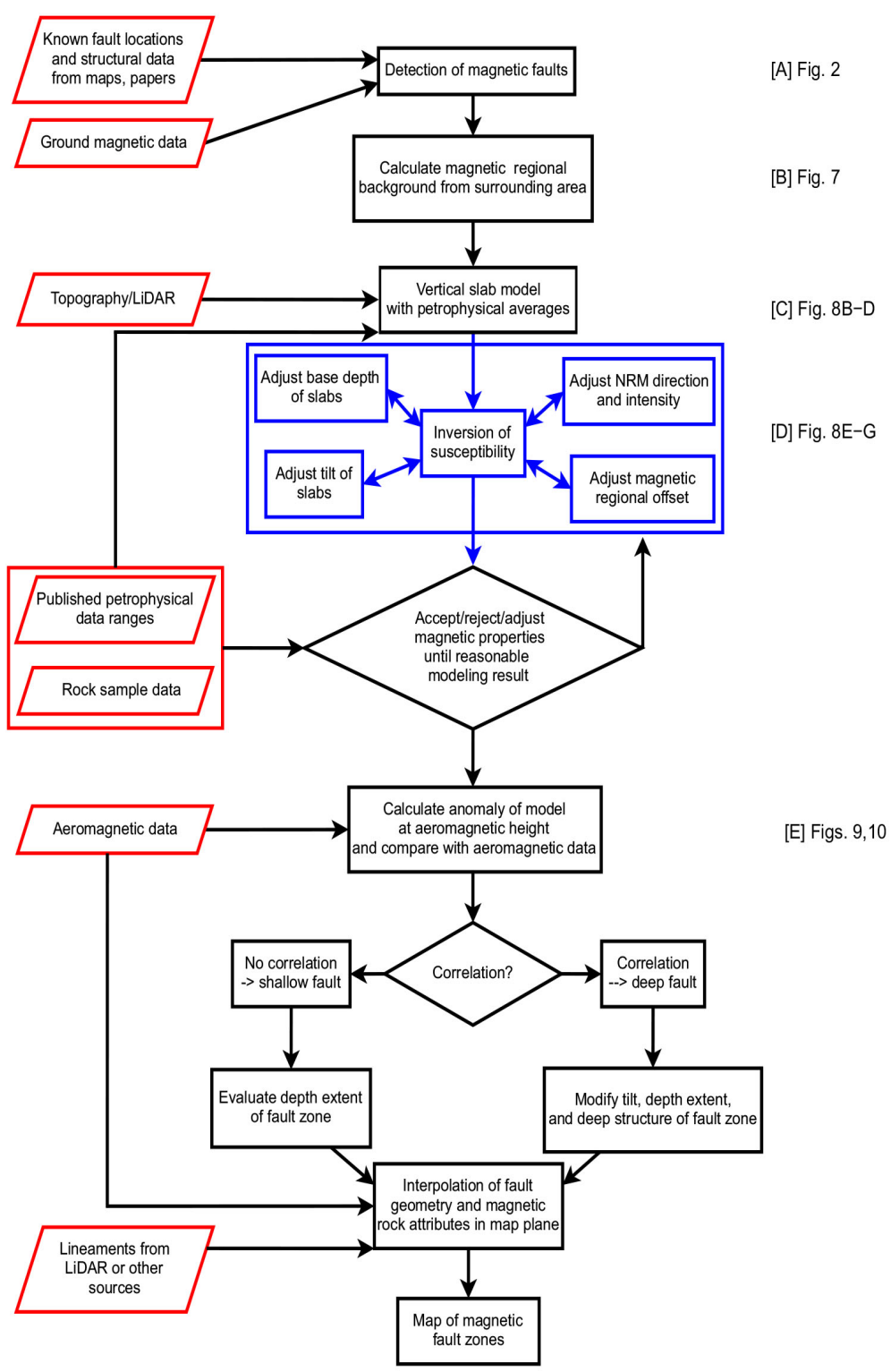

Figure 5. Workflow for mapping of magnetization in faults.

lineaments, or field studies, because positioning methods were not as accurate as they are today. In this work, the line data for the model were extracted from the grids of the ground-magnetic data and positioned according to the faults from Furnes et al. (1988) (Fig. 2C).

[Step B] All magnetic models must account for the regional magnetic background field, which affects the modeling results. In the modeling process it is important to select an appropriate regional magnetic background field. Calculating the regional magnetic background field starts with the choice of an area in the magnetic anomalies map that includes both the faults' magnetic anomalies and areas with no distinct anomalies. The latter are representative of the background field (see Electronic Supplement 2), whereas areas with the faults' magnetic anomalies are excluded. Mean value and standard deviation of the remaining magnetic anomalies are then calculated. This procedure results in a range for the regional magnetic background field that can be used for models. 

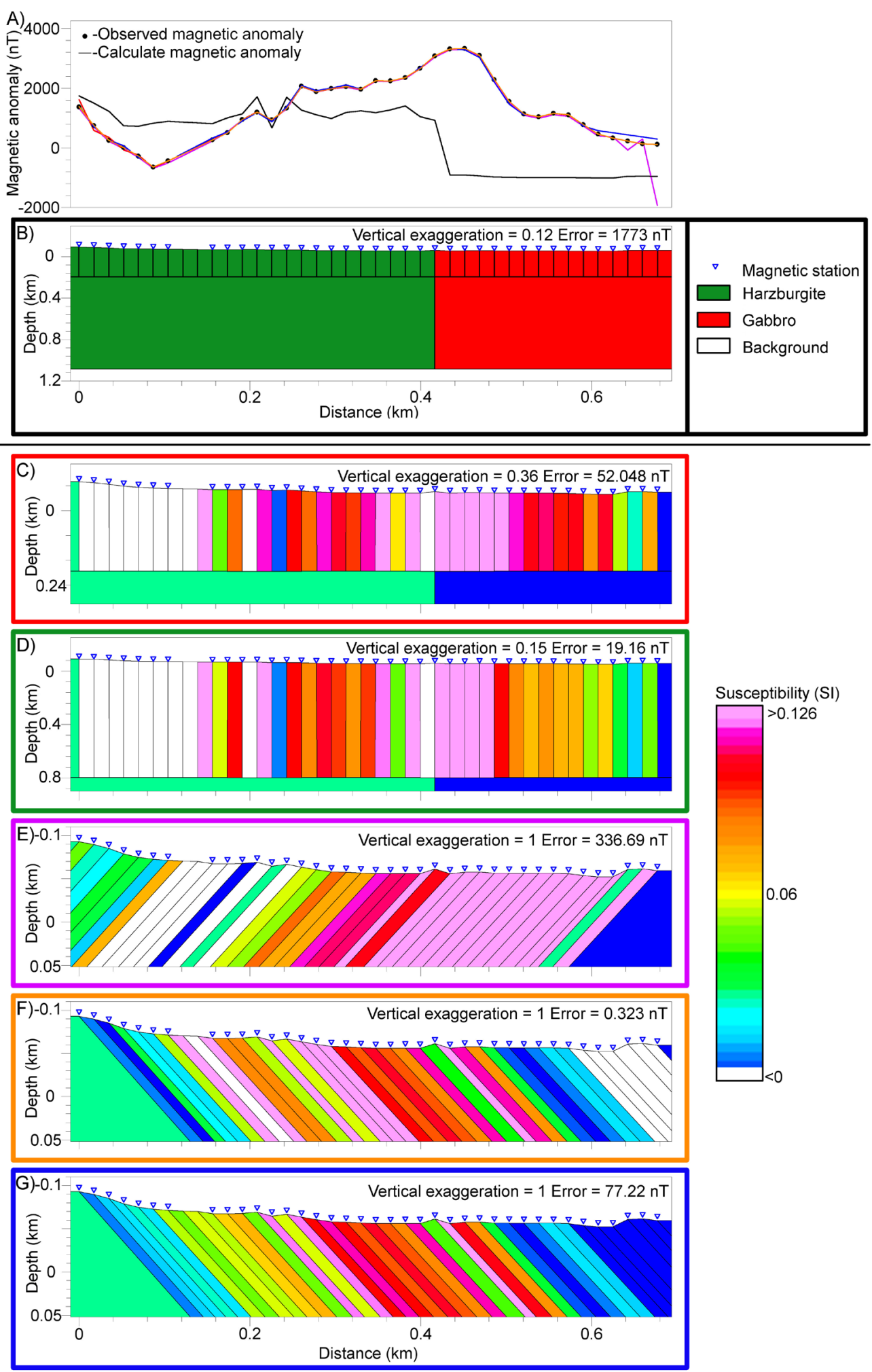

Figure 6. Model development along model line 13 (see Fig. 2C for location). (A) Calculated and observed magnetic anomaly; the calculated anomalies for panels $C-G$ are color-coded with the frame of each model but cover each other to a high degree. (B) Vertical slab model with property averages of the rock types with a very poor fit (black line in panel A). (C) The result after inversion with the base of the model at $200 \mathrm{~m}$. (D) The result after inversion with the base of the model at $800 \mathrm{~m}$. (E) Result with fault dip of $45^{\circ}$ towards NW. (F) Result with fault dip of $45^{\circ}$ towards SE. (G) The result after manually removing negative susceptibilities and unreasonably high susceptibilities by either increasing or decreasing NRM, while still maintaining a $Q$ value that is within a reasonable range. 
[Step C] Topographic data are necessary to create the ground-air surface in the model. The sampling distance of the topography and ground-magnetic survey defined the minimum thickness of a single slab. Here, LiDAR allowed for a sampling distance of $1 \mathrm{~m}$. There were discrepancies of $\pm 10 \mathrm{~m}$ between the magnetometer-mounted GPS elevation and the LiDAR elevation data. Because the LiDAR elevation data are assumed to be the better source for precise elevation, we calculate the magnetometer sensor elevation by adding a value of $2 \mathrm{~m}$, the sensor height above ground, to the LiDAR elevation data.

\section{Model}

In the case of a skewed angle between the ground-magnetic profile and fault strike, the 2D modeling algorithm must be corrected with a rotation of the model profile. This adjustment was made in the program GMSYS2D by changing the profile azimuth. This will project the magnetic data into a new direction, but the topography will not match the new profile location. Therefore, the topography is projected onto the new model line by taking the cosine of the $x$-axis position along the original profile using Eq. 2, where $X_{0}$ is the original position, $\theta$ the angular difference between the original model profile azimuth and the corrected one, and $\mathrm{X}_{\text {new }}$ the new $\mathrm{X}$ positions of the topography.

$$
X_{\text {new }}=X_{0} * \cos (\theta)
$$

[Step D] Model development starts with a series of vertical slabs using average values for the magnetic properties of the rock types (Fig. 6B). The deeper part of the model below the slabs, and the background outside the displayed profile, is populated with average values of the rock types. The deeper part can be modified at a later stage based on the modeling of aeromagnetic data. The starting model considers only lithological boundaries and the fault location. The model is split vertically at the fault location. In the next step, the model is divided into minor slabs, with widths equal to, or larger than the profile point spacing. If there is a flat area with no change in the magnetic anomaly, the width of the associated slab can be changed to a larger area. To compensate for the regional background field the calculated data can be adjusted with a regional offset or $\mathrm{dc}$ shift. This value can be raised or lowered later if inversion values are either too high or too low.

The calculated magnetic response to the starting model (Fig. 6B) had a very poor fit (Fig. 6A). The inversion is now run for the susceptibility of the slabs in the fault zones while the surrounding background values and NRM remain unchanged. Two different basal depths of $200 \mathrm{~m}$ and $800 \mathrm{~m}$ have been tested (Fig. 6C, 6D, respectively). After running an unconstrained inversion for the susceptibility, this leads to an almost perfect match between the observed and calculated values. The pattern of the susceptibilities in both models is similar, but has slightly different values. In the next steps, a dip of $45^{\circ}$ to the NW and a dip of $45^{\circ}$ to the SE were implemented leading to the inversion results shown in Fig. $6 \mathrm{E}, 6 \mathrm{~F}$, respectively. If no structural constraints exist, all models shown from Fig. $6 \mathrm{C}-\mathrm{F}$ are valid from a modeling perspective. The model in Fig. $6 \mathrm{E}$ has negative susceptibilities within the harzburgite slabs, and many of the gabbro slabs have a higher susceptibility than measured in the gabbro samples (Electronic Supplement 1, Table 1). Therefore, the inversion results do not reflect the correct geology. Tilting of blocks towards the SW (Fig. 6F) reduced the negative susceptibility values and resulted in geologically reasonable susceptibilities within the harzburgites. In case the model in Fig. $6 \mathrm{~F}$ has the correct (predefined) dip direction, an unreasonably high and negative susceptibility value can be manually changed. Such changes were made by either increasing or decreasing NRM values, and altering the NRM directions while maintaining a reasonable range of the Koenigsberger ratio (Q) values (Fig. 6G). The $Q$ value is the ratio between the NRM and the induced magnetization. Finally, inversion bias by abrupt changes/alternations in susceptibility of adjacent slabs needs to be corrected until a model with reasonable geological values for the magnetization is reached. 
[Step E] As discussed above, the ground-magnetic anomalies accentuate near-surface features while the aeromagnetic data reflect deeper structures and can be used to detect deep-reaching faults. If the aeromagnetic anomalies correlate with the faults identified by the ground-magnetic data, a joint model can be developed matching both datasets. If instead the aeromagnetic data do not fit with the overall trend of the ground-magnetic data, it can be concluded that the fault model may not extend deep into the subsurface. This will be addressed in the modeling area shown in Fig. 8.
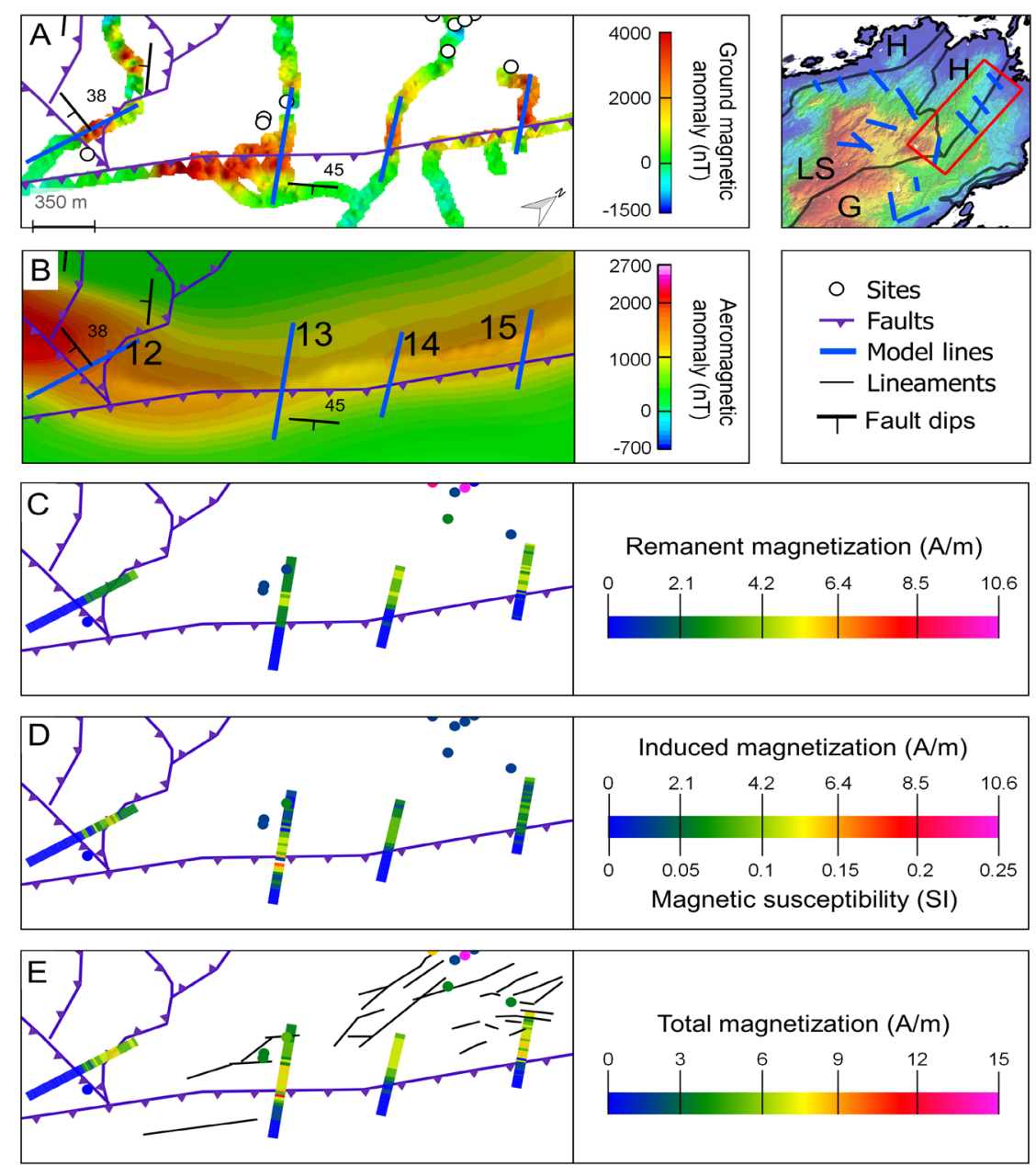

Figure 7. Modeling results for ultramafic-gabbroic fault contacts (area is outlined in red in upper-right elevation map: for scale, refer to Fig. 1B, LS-layered series, H-harzburgite, G-gabbro): (A) site locations, model line locations and known faults with respective dips superimposed on ground-magnetic data; $(B)$ on aeromagnetic data; $(C)$ NRM intensities $\left(J_{r}\right)$ of modeled slabs and sites (colored circles); (D) susceptibility (susc) and induced magnetization ( $J_{i}$ ) of modeled slabs and sites; (E) total magnetization $\left(J_{t}\right)$ of modeled slabs, and sites with lineaments from LiDAR. Note: the colors for the model slabs represent the locations where the slabs meet the surface.

\section{Results}

The modeling workflow has been applied to faults in the central and northern parts of the LOC focusing on four areas, chosen to represent different fault scenarios. The areas and the modeled line locations are displayed in Fig. 2. The first area is at the fault contact between ultramafic rocks (harzburgite, layered series) and gabbro, which correlates with an aeromagnetic high. The second area is within the gabbroic unit and while this lacks correlation with the aeromagnetic anomaly at the fault localities, it is characterized by a minor magnetic anomaly in the ground-magnetic data. The third area includes faults that are within the layered series and follow a minor aeromagnetic anomaly. The fourth area is on the 

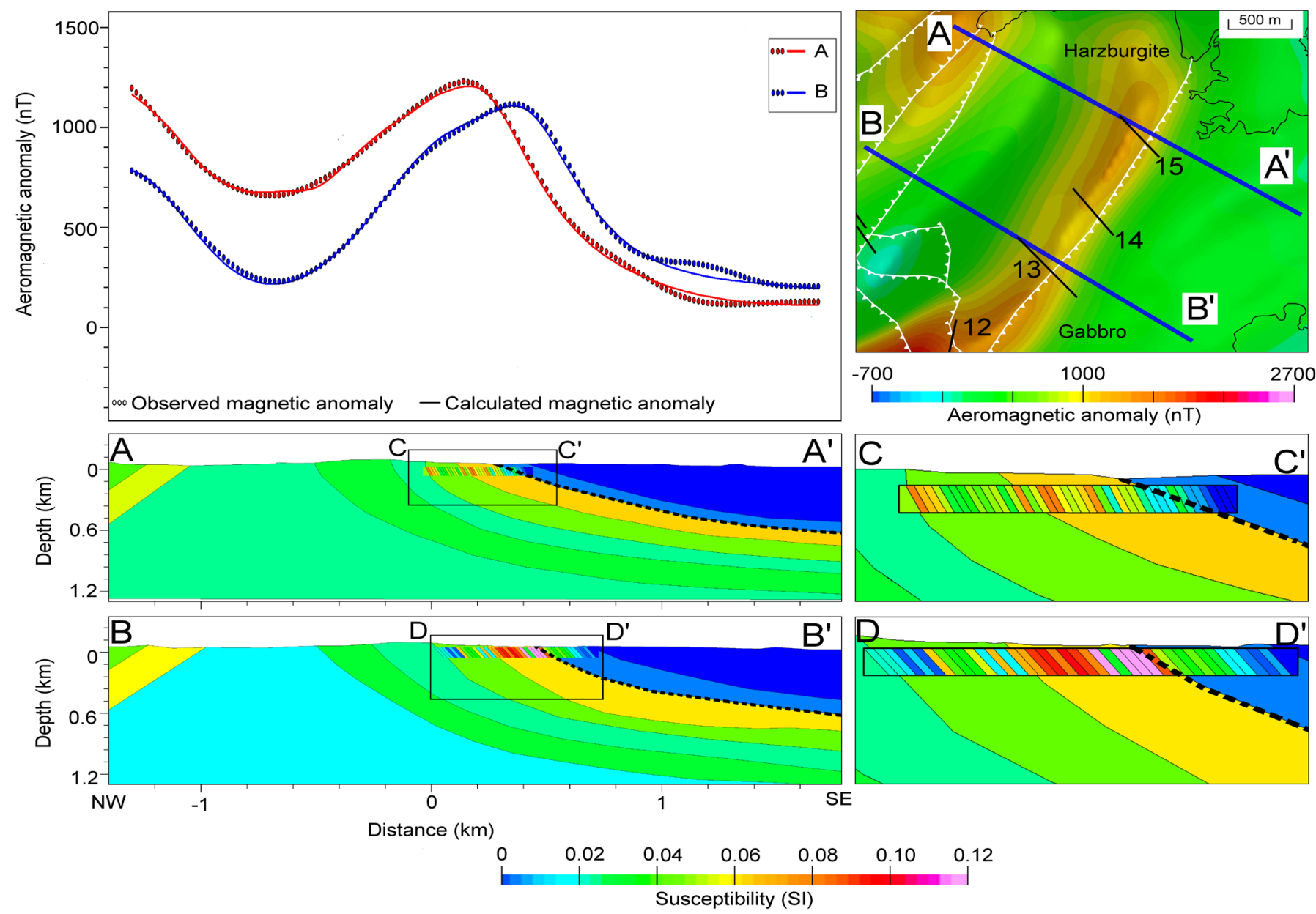

Figure 8. (Top) Calculated and observed aeromagnetic anomalies for the model lines $A-A^{\prime}$ and $B-B^{\prime}$ with profile locations. (C-C') $C l o s e$ up of model line $A-A$ ' overlain with a clipped section of the ground-magnetic model line 15. ( $\left.D-D^{\prime}\right)$ Close up of model line B-B' overlain with a clipped section of the ground-magnetic model line 13.

northern part of the island where the harzburgite is bound by the layered series and includes a series of faults adjacent to the contact.

Modeling results are shown in Figs. 7, 9, 10, \& 11 for the four different areas. Each figure consists of 5 map panels, where the different magnetic properties have been derived from the modeling/inversion results. Panel A displays the ground-magnetic data together with the fault locations and structural information. Panel B shows the gridded aeromagnetic data together with the fault locations. Panels C, $D$, and $E$ show the NRM, the induced magnetization or alternatively magnetic susceptibility and the total magnetization of modeled slabs with associated average values for the sample sites, respectively, together with the fault locations. The induced magnetization is the product of susceptibility and the Earth's magnetic field at the location. The Earth's field at Leka is $52166 \mathrm{nT}(41.35 \mathrm{~A} / \mathrm{m})$ with a declination of $3.2^{\circ}$, and Inclination of $75.7^{\circ}$ (IGRF, 201011 th generation, Finlay et al., 2010). Panel D can also be read as susceptibility, by using the respective scale. Panel E includes the LiDAR lineament interpretation as discussed below.

The results for area 1 are displayed in Fig. 7. The ground-magnetic anomaly data in Fig. 7A show a distinct high with maximum amplitude of $3000 \mathrm{nT}$ and $4000 \mathrm{nT}$ at the faults, which coincides with the lithologic contact between the gabbro and the ultramafic rocks, striking in a NE-ENE direction. There is a clear correlation between this contact zone and the aeromagnetic anomaly (Fig. 7B). Four lines have been 

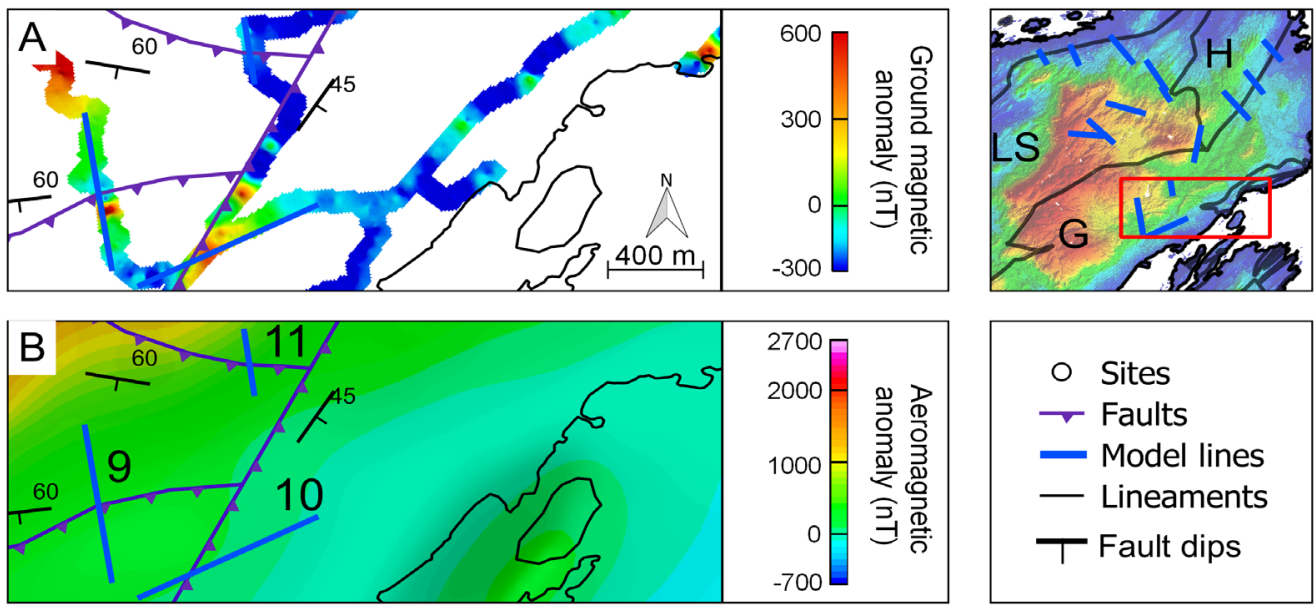

O Sites

$\checkmark$ Faults

- Model lines

- Lineaments

T Fault dips
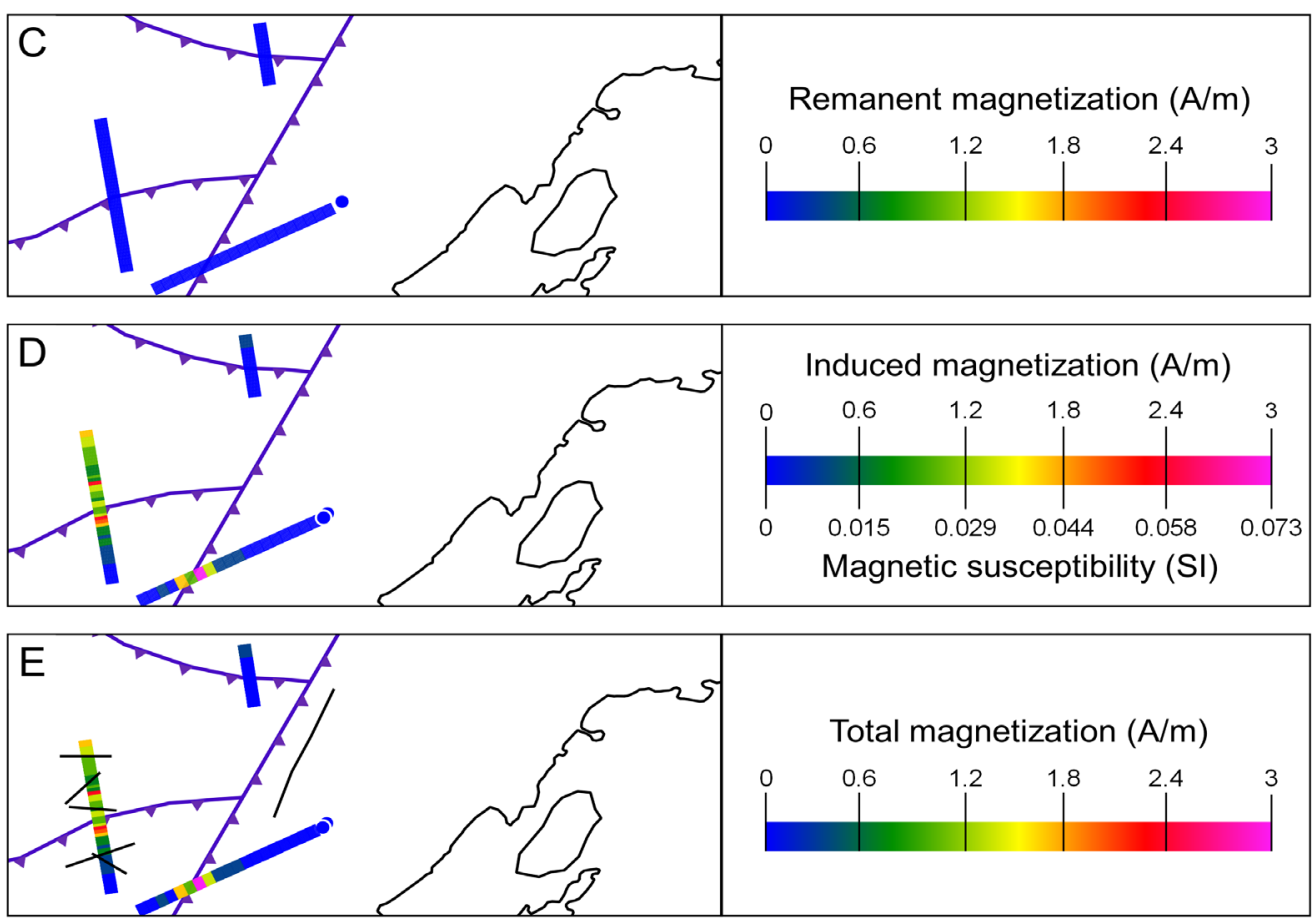

Figure 9. Modeling results for gabbroic fault contacts (area is outlined in red in upper-right elevation map: for scale, refer to Fig. 1B, LS-layered series, H-harzburgite, G-gabbro): (A) site locations, model line locations and known faults with respective dips superimposed on ground-magnetic data; (B) on aeromagnetic data; $(C)$ NRM intensities $\left(J_{r}\right)$ of modeled slabs and sites (colored circles); (D) susceptibility (susc) and induced magnetization $\left(J_{i}\right)$ of modeled slabs and sites; $(E)$ total magnetization (J) of modeled slabs, and sites with lineaments from LiDAR. Note: the colors for the model slabs represent the locations where the slabs meet the surface.

modeled; model line 12 crosses the contact between layered series and gabbro, and model lines 13-15 cross the harzburgite-gabbro contact. The models (Fig. 7C, 7D, and 7E) show an increase in induced, remanent, and total magnetization on the ultramafic footwall side of the fault.

Susceptibilities and total magnetization on model line 13 have a high value just south of the fault location whereas the other lines show an increase in susceptibility on the footwall. This may indicate a misplacement of the fault position. On model line 15, two lineaments mapped by LiDAR data cross the line where the magnetization values are near the average values of the harzburgite. The same applies to model line 13. It is uncertain how these lineaments relate to the magnetized fault zone, because there is little rock exposure due to vegetation. 

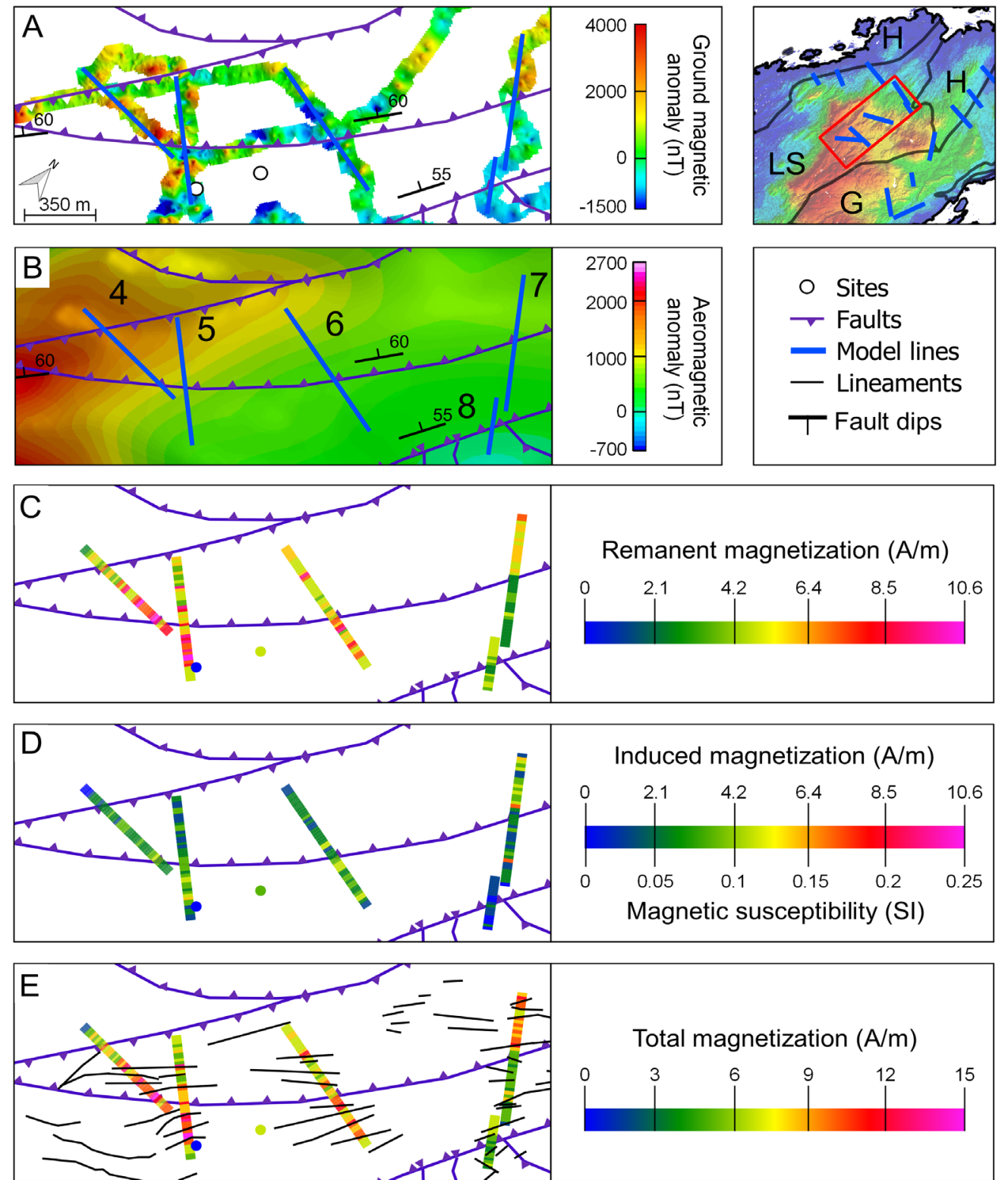

Figure 10. Modeling results for layered series fault contacts (area is outlined in red in upper-right elevation map: for scale, refer to Fig. 1B, LS-layered series, H-harzburgite, G-gabbro): (A) site locations, model line locations and known faults with respective dips superimposed on ground-magnetic data; (B) on aeromagnetic data; (C) NRM intensities $\left(J_{r}\right)$ of modeled slabs and sites (colored circles); (D) susceptibility (susc) and induced magnetization $\left(J_{i}\right)$ of modeled slabs and sites; (E) total magnetization $\left(J_{t}\right)$ of modeled slabs, and sites with lineaments from LiDAR. Note: the colors for the model slabs represent the locations where the slabs meet the surface.

On model line 13 the modeled magnetizations are higher than the measured samples values at one site location; however, the total magnetization is similar, indicating a larger contribution from the NRM (Fig. 7B). The other sample locations have magnetic properties consistent with the modeled values. Model lines 13 and 14 show a decrease in magnetization in the harzburgite north of the fault. Model line 15 has a slight increase near the northern end of the model line. This correlates with some lineations which could represent small faults, and hence an increase in magnetization.

Lines 13 and 15 were modeled using aeromagnetic anomaly data with an angle perpendicular to the fault at the location where the ground-magnetic profiles cross the fault line. In Fig. 8, the groundmagnetic models are projected onto the aeromagnetic models and both models are shown with the modeled and observed aeromagnetic data; the latter show an excellent match and are therefore hard to distinguish from each other. The length of the aeromagnetic model was made to enclose the entire magnetic 

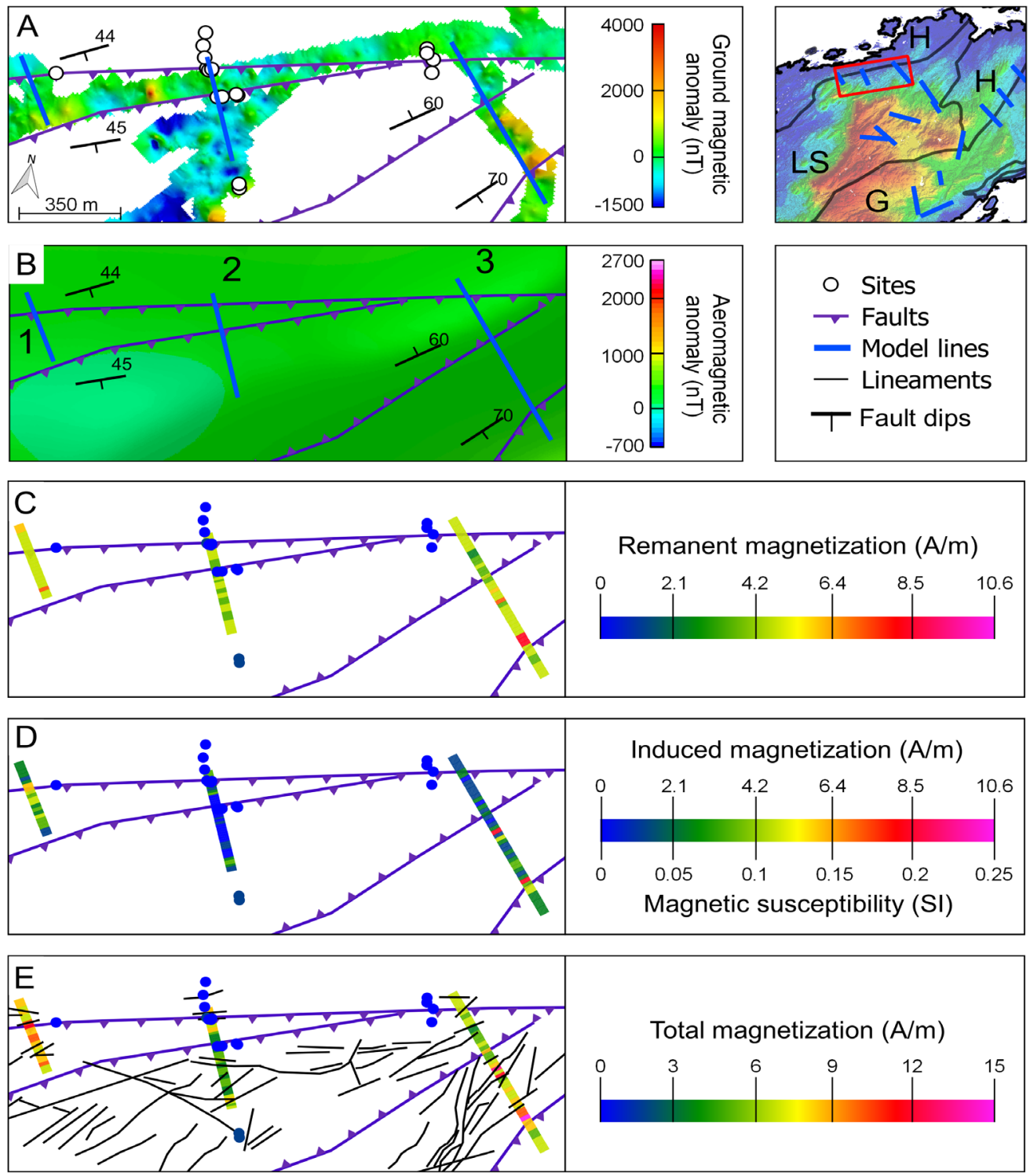

Figure 11. Modeling results for layered series-harzburgite fault contacts (area is outlined in red in upper-right elevation map: for scale, refer to Fig. 1B, LS-layered series, H-harzburgite, G-gabbro): (A) site locations, model line locations and knownfaults with respective dipssuperimposed on ground-magnetic data; (B) on aeromagnetic data; (C)NRM intensities ( $J_{r}$ ) of modeled slabs and sites (colored circles); (D) susceptibility (susc) and induced magnetization ( $\left.J_{i}\right)$ of modeled slabs and sites; (E) total magnetization $\left(J_{t}\right)$ of modeled slabs, and sites with lineaments from LiDAR. Note: the colors for the model slabs represent the locations where the slabs meet the surface.

anomaly over the fault. The ground-magnetic models were simplified and provided the starting models resulting in a simpler aeromagnetic model with fewer bodies and a listric fault.

The modeled fault geometry in Fig. 8 is an improvement on previous work by Michels et al. (2018), where this major fault was modeled with only three different petrophysical units (gabbro, magnetic fault zone, and ultramafic rocks). The modeled fault zone is approximately $400 \mathrm{~m}$, and the highly magnetic zone is approximately $200 \mathrm{~m}$ thick. Comparison with lineaments mapped using LiDAR indicates that this fault zone consists of a series of parallel zones of higher magnetization (see Fig. 7B, 7E).

The next model area is within the gabbro (Fig. 9). Because the gabbro has a significantly lower magnetization than the ultramafic rocks, the magnetization scales used in Fig. 9 cover a smaller range than 
in the other modeling figures. The ground-magnetic anomaly shows little variation in total magnetization along model line 11, but there are local highs adjacent to the fault on modeling lines 9 and 10 . These highs lead to modeled total magnetization values higher than in any of the gabbro samples. The strongest gabbro NRM is $0.3 \mathrm{~A} / \mathrm{m}$, which is $10 \%$ of the highest magnetization in the model. This location is on the leeward side of the island with more vegetation, and few gabbro exposures. We do not exclude the possibility that other rocks may be present below the vegetation. There are some lineaments parallel to the fault, but these do not correlate with the high ground-magnetic anomaly nor with the modeled section properties.

The model area in the layered series is shown in Fig. 10. There are large variations within the models. Model lines 4 and 5 show increased magnetization on the footwall of the southern fault. On model lines 5 and 6 , the modeled NRM and susceptibilities are well above the measured site values. The short model line 8 barely shows any variation. On model line 7, there is a higher magnetization on the hanging wall side of the fault. This is not consistent with the other model lines 5 and 6 , where the higher magnetization is on the footwall side of the fault.

The last model is in an area with both harzburgites and the layered series. Fig. 11 shows the model lines $1-3$, and covers four faults. Model lines 1 and 2 have a relatively high total magnetization compared with previous models. Model line 1 has an average magnetization that is higher than in all other lines. Two faults with similar orientations are near to this fault. Model line 1 shows a higher magnetization above the northern fault and modeled values that are well above the sample values. For model line 2 , there is a lower magnetization where it crosses the southern fault. Model line 3 is crossing three faults with different fault dips, two that dip towards the SE and the one in the middle that dips towards the NW. The strongest magnetization is at the southernmost fault with a total magnetization between 13.5 and 15 $\mathrm{A} / \mathrm{m}$ (Fig. 11E). This zone of high magnetization correlates with the topography. Here we observed that the model values are higher than the sampled values.

\section{Discussion}

\section{Comparison of model values with sample values}

The magnetic attributes of the slabs have been assigned lithology according to location on the geologic map. Fig. 12 shows the sample dataset and the slab model magnetic properties in the form of violin plots. The violin plot is a sideways kernel density plot (Hintze \& Nelson, 1998; Haslwanter, 2016). The shape of the violin plot shows the distribution of the magnetic properties. The wider the violin plot the more common is the corresponding magnetic property value.

The majority of samples were collected outside the fault zones (Figs. 7, 9, 10, \& 11). The violin plots generally show that the mean susceptibility and NRM values for the slab models are higher than the samples' values, indicating a higher magnetization adjacent to faults. The mean harzburgite's $Q$ value and the layered series NRM and $Q$ values are lower for the modeled slabs than for our samples but still within the range of the samples' values.

Both the layered series and the harzburgite samples have high susceptibilities and NRM values. These rocks are serpentinized to various degrees. According to lyer et al. (2008), most of the serpentinization within the LOC occurred at the ocean-floor, and later stages with the formation of antigorite may have been related to the Caledonian regional metamorphism after obduction. However, even at the present day, there is ongoing serpentinization in cracks as documented by Okland et al. (2012). 

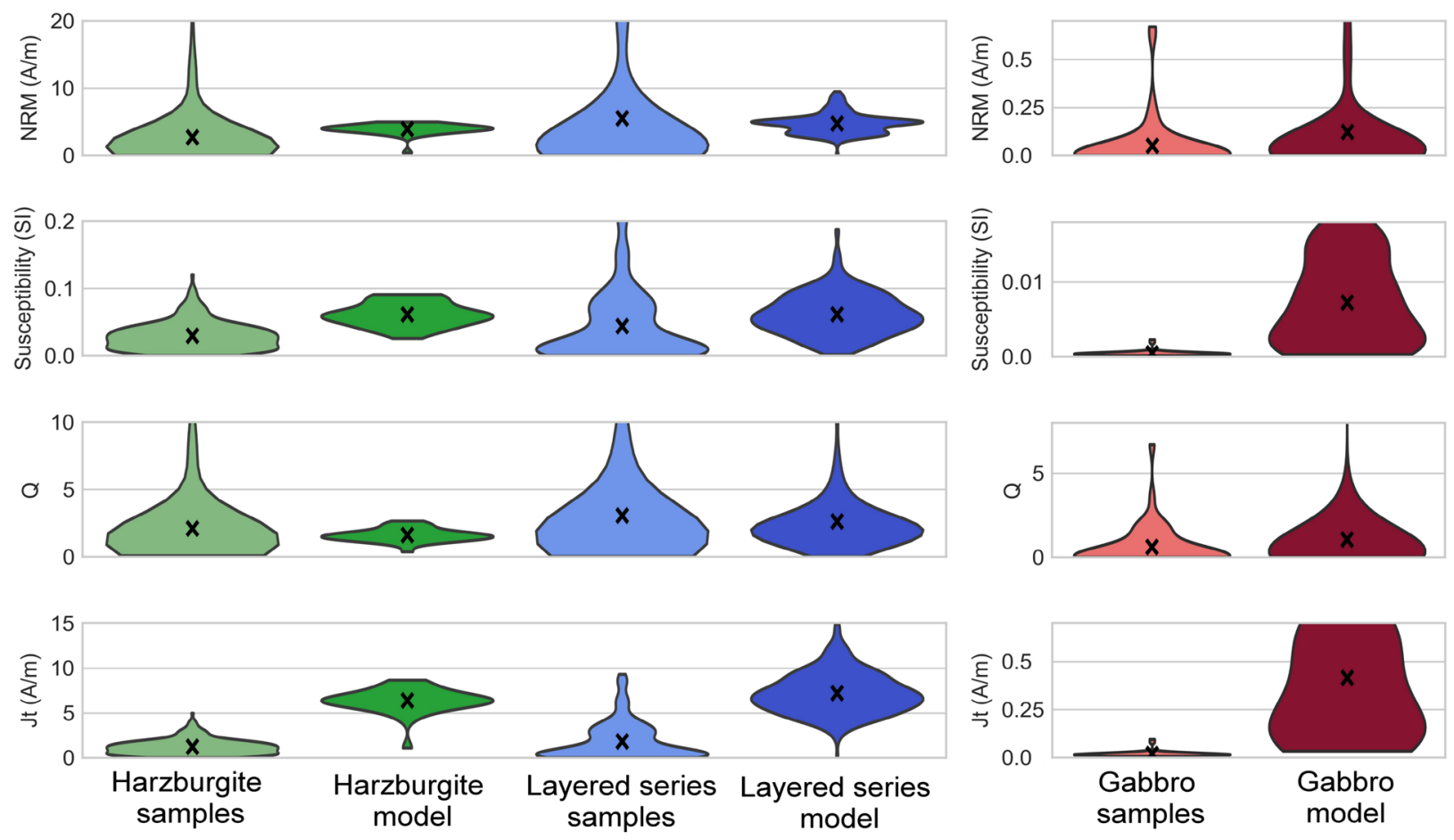

Figure 12. Violin plots of the Leka sample data and the modeled slabs. X marks the mean value for the property of the rock unit.

The susceptibility of the gabbro is higher in the slab model than the samples values, which may be explained by misplacement of the harzburgite-gabbro boundary on the geologic map in Fig. 7, suggesting that some of the slabs that are marked as gabbro should be harzburgite. Most of the area is farmland with tree cover; therefore, the exact contact location may not be correctly determined by geological mapping. Alternatively, the modeled slab could also be a transition zone with mixing of gabbro and ultramafic rocks, which would result in higher total magnetization than expected for the gabbro but lower than for the ultramafic rocks.

The gabbro samples have low susceptibility and NRM. There are a few sites within the gabbro that have a higher NRM than the other gabbro samples, but upon closer inspection these gabbros occurred near to the fault contact and showed inclusions of dunite which are likely the source for the increased magnetization.

The NRM directions for the sites and slab models are given in Electronic Supplement 3. There is generally less scatter in the model values than in the sample data. This is due to the workflow, where all slab models get assigned the average value for the lithology's NRM before inversion. After the inversion is run, only susceptibility values which fell outside the expected range were modified. Therefore, changes in NRM may not always be recognized. The largest scatter is within the layered series, which agrees with the scatter of sample directions.

The modeling results from 15 ground-magnetic profiles show a wide range of susceptibilities and NRMs in the fault zones. The compilation of the results in Figs. 13 \& 14 is presented as the total magnetization of the slab models. 

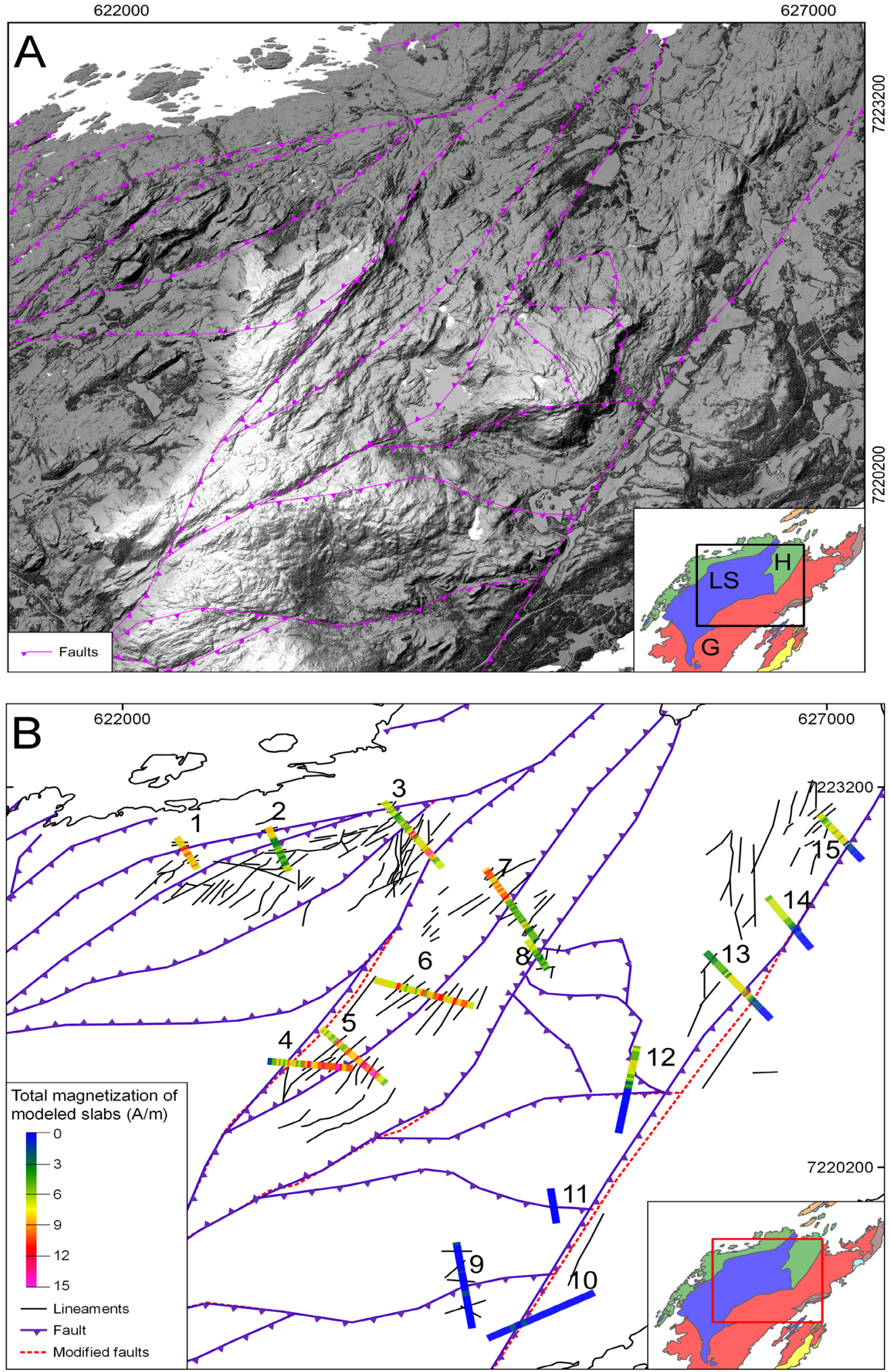

Figure 13. (A) LiDAR grid with $1 \mathrm{~m}$ spacing used in the lineation mapping, with faults shown from Furnes et al. (1988). (B) Faults, lineaments, and compilation of total magnetizations $\left(J_{t}\right)$ of modeled slabs. Dotted red line indicates modified faults. Projection: UTM zone 32N, Datum: WGS84. 

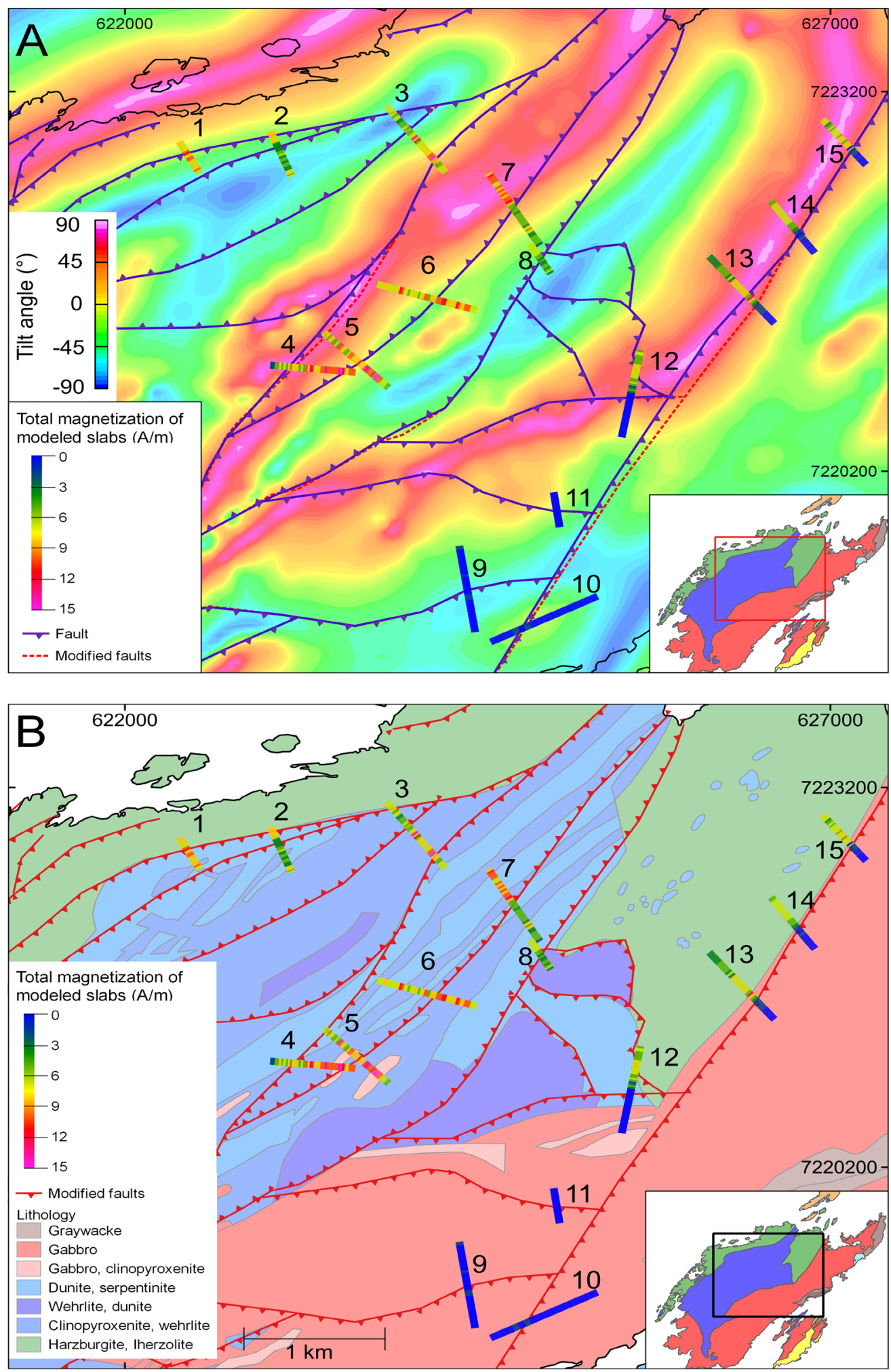

Figure 14. (A) Faults and compilation of total magnetizations ( $\left.J_{t}\right)$ of modeled slabs superimposed on the tilt angle (TA) of the aeromagnetic data. (B) Faults and compilation of total magnetizations $\left(J_{t}\right)$ of modeled slabs superimposed on the geologic map with subunits, modified from Pedersen et al. (2011). Projection: UTM zone 32N, Datum: WGS84. 


\section{Enhanced magnetization in fault zones}

Along the faults, the permeability of the rocks is higher allowing higher fluid flow. The increase in magnetization along the faults may be explained by a local increase in magnetite formed during serpentinization. Many authors have noted that serpentinization can cause increased magnetization due to the creation of magnetite (cf., Blakely et al., 2005; Evans et al., 2013).

The results are more consistent for model lines 12-15 which cross the large fault zone (Figs. 7, 13 \& 14) that separates the gabbroic and ultramafic rocks, the latter including both the layered series and harzburgites. The magnetic zone in the faults has a maximum thickness of $400 \mathrm{~m}$ as derived from the aeromagnetic anomalies. The highly magnetized zone has a thickness of approximately $200 \mathrm{~m}$, with somewhat varying magnetization as derived from the ground-magnetic data. This fault zone is the best example of this case study for a magnetized zone likely created by serpentinization.

Other magnetized zones correlating with faults in ultramafic rocks are found in model lines 1, 2, 3, and 7 (Figs. 10,11, 13, \& 14). Due to the clustering of faults, the magnetized zones may overlap, and therefore it is not easy to give a good estimate of the width of the magnetized zones. The geometry of the faults varies across the complex from listric to sub-vertical. The highest modeled total magnetization in the ultramafic rocks is $14.9 \mathrm{~A} / \mathrm{m}$ on model line 3 .

Profiles 4-6 (Figs. 10, 13, \& 14) show widespread magnetized patterns, and model line 8 does not show a distinct anomaly. An explanation could be that the rock was first serpentinized and then faulted, which would mean that the faulting may not have significantly affected the magnetization of the serpentinized rock. Alternatively, either the rock's composition or conditions may not have been ideal for serpentinization to create magnetite or the fault's location is misplaced.

The final question addresses the increased magnetization of up to $3 \mathrm{~A} / \mathrm{m}$ in the gabbroic area modeled with profiles 9-11 (Figs. 7, 13, \& 14). Although there are no samples directly above the fault (Figs. 7, 9, $10, \& 11)$, the gabbro's magnetic properties are generally weak with an average NRM of $0.05 \mathrm{~A} / \mathrm{m}$ and susceptibility of 0.0004 (SI) (see Table 1). A gabbro sample taken at another location adjacent to a fault has an average NRM of $0.00004 \mathrm{~A} / \mathrm{m}$ and susceptibility of 0.0005 (SI) and confirms the weak magnetization of these rocks. The increase in magnetization along some of the faults in the gabbro could be due to increased serpentinization caused by fluids migrating within the faults. It is also possible that during faulting, slivers of serpentinized ultramafic rocks were incorporated into the fault rock. This is supported by an inclusion of serpentinized dunitic rock in the gabbro between model lines 12 and 11 (Fig. 2). Samples from this large fragment have an average NRM of $20 \mathrm{~A} / \mathrm{m}$ and susceptibility of 0.207 (SI). There is a large magnetic anomaly detected by the ground magnetometer at this location.

\section{Lineament mapping and fault interpretation}

By applying this workflow (Fig. 5), the distribution of the magnetization and the geometry of the faults can be determined at the meter scale using ground-magnetic data. In the next step (Fig. 5F), LiDAR data were included to improve the location of the faults. The shaded relief of the LiDAR data, which enhances linear topographic features, revealed that many lineaments are parallel to the primary fault trend. Lineaments were mapped when near the model lines (Fig. 13). These lineaments complement the previously mapped faults and lineaments (Furnes et al., 1988; Titus et al., 2002).

However, comparison between these lineaments and our slab models did not show a clear correlation. As a consequence, some of the fault locations were adjusted by combining the modeling results with the 
new LiDAR data, as shown in Fig. 13. From model lines 13-15, the main fault should be shifted towards the southeast based on the location of the magnetic anomaly high on model line 13 . This area has little exposure and is covered by vegetation. Here, the geophysical interpretation can help in refining the geologic contacts.

Fig. 14A compares the total magnetization of the model lines with the tilt angle (TA) of the aeromagnetic data. The TA is a combination of gradients that responds well to both shallow and deep sources (Miller \& Singh, 1994). In a simple model with one vertical-sided magnetic source, the maximum of the TA is located over the source, crosses through zero near its edges and is negative outside the source region (Miller \& Singh, 1994). Here, the area defining the fault zone with its enhanced magnetization can be regarded as such a source. The highest values of the TA are therefore expected to be found over the magnetized zones. However, edge detection by the value of zero of the TA will not be precise as both dip direction and depth of the magnetized zone will bias the location of the zero-crossover line of the TA. In such a case, the purpose of the TA is both the enhancement of short wavelength related to anomalies of potential fault zones, as well as pushing minor amplitudes to higher TA values by the equalization effect of the TA filter method. Along model lines 12-15, at the contact of the gabbro with the ultramafic rocks, there is a correspondence between the high TA anomaly and the high modeled magnetizations. Along model line 7 , in the layered series, the high magnetizations correspond to a high TA anomaly. This correspondence does not apply to model lines 4,5 and 6 with a low magnetization over the high TA anomaly.

Model line 1 has a higher magnetization though it is on the lower side of the TA anomaly. Lines 2, 3, and 8 have lower magnetization values that correspond to a negative TA anomaly and higher magnetization values where the TA anomaly is positive. The modeling results were compared with a recent geologic map with detailed sub-units for the LOC (Fig. 14B; Pedersen et al., 2011).

The map in Fig. 14B shows gabbroic slices within the layered series. Despite the major part of the gabbro being weakly magnetic, the mapped gabbroic slices coincide with higher magnetic anomalies and modeled magnetizations on model lines 4 and 5 . These magnetic anomalies could be the result of an edge effect caused by the contrast in the magnetic properties between the gabbro and the layered series. The gabbro will not fracture as easily as the olivine-rich dunite, and the fluid may go around the less permeable gabbro, increasing the degree of serpentinization of the layered series leading to a higher magnetic anomaly. The presented work shows that many of the ground-magnetic anomaly highs correlate with aeromagnetic anomaly highs. Misfits are found mostly in the layered series indicating that there must be an appreciable volume of magnetic rocks at large depths, which are possibly overlain by less magnetic rocks, which are captured by the ground-magnetic data.

\section{Conclusions}

1. Using an integrated approach, a workflow was developed using ground and aeromagnetic data, LiDAR elevation data and sample properties to model fault zones. The fault zones were modeled using tilted slabs. The variation in total magnetization of the slabs was derived by applying an unconstrained inversion for the susceptibilities, with fixed NRM values defined by sample averages. Where necessary, susceptibility and/or NRM were edited to make the model geologically reasonable. Model properties were constrained by the range of rock samples' properties. This workflow was developed for Leka but can be applied in other geological settings where an increase in magnetization occurs in fault zones. 
2. The magnetized zone associated with the largest fault between the ultramafic and gabbroic rocks gave the most consistent result (model lines 12-15). The width of the highly magnetic fault zone is estimated to be approximately $200 \mathrm{~m}$ and is modeled as a listric fault. Other faults in the ultramafic lithology showed distinct magnetization but were less consistent across different models. Some of the mapped faults lack correlation with the ground-magnetic anomalies. This could be explained by a variable degree of serpentinization rather than structural contacts or by a source depth that is below the sensitivity of the ground-magnetic data.

3. The enhanced magnetization in the fault zones in ultramafic rocks is likely due to serpentinization, which can result in a local increase in the rocks' magnetite content. This observation is supported by the higher averages of the modeled slabs' total magnetizations, clearly above the background magnetization of the LOC as calculated from surface samples.

4. The locations of some faults were refined using modeling results in combination with lineament interpretation of the LiDAR data. The dips of some of the LOC faults were estimated by modeling of the magnetic data and structural contouring. These range from sub-vertical, as previously suggested by Titus et al. (2002), to lower angles between 45 and $60^{\circ}$.

Acknowledgments. We thank the reviewers Aziz Nasuti and Ken Kodama and the editor Trond Slagstad. The Research Council of Norway grant 222666 to S. McEnroe supported this research. The Geological Survey of Norway kindly provided the latest aeromagnetic data. The fieldwork could not have been done without the many field assistants, Geertje ter Maat, Andrea Biedermann, Hedda Jensen, and Alexandra McEnroe. Jostein Hiller was a guide and boat driver to some of the smaller islands around Leka, and Rolf Pedersen graciously provided his expertise on Leka geology and field guidance.

\section{References}

Albrektsen, B., Furnes, H. \& Pedersen, R. 1991: Formation of dunites in mantle tectonites Leka Ophiolite Complex, Norway. Journal of Geodynamics 13, 205-220. https://doi.org/10.1016/0264-3707(91)90039-H.

Alexander, R.J. \& Harper, G.D. 1992: The Josephine ophiolite: an ancient analogue for slow-to intermediate-spreading oceanic ridges. Geological Society, London, Special Publications 60, 3-38. https://doi.org/10.1144/GSL.SP.1992.060.01.02.

Austrheim, H. \& Prestvik, T. 2008: Rodingitization and hydration of the oceanic lithosphere as developed in the Leka ophiolite, north-central Norway. Lithos 104, 177-198. https://doi.org/10.1016/j.lithos.2007.12.006.

Barnes, I., Rapp, J.B., O'Neil, J.R., Sheppard, R.A. \& Gude, A.J. 1972: Metamorphic assemblages and the direction of flow of metamorphic fluids in four instances of serpentinization. Contributions to Mineralogy and Petrology 35, 263-276. https://doi.org/10.1007/BF00371220.

Blakely, R.J. 1995: Potential theory in gravity and magnetic applications: Cambridge University Press, 441 pp. https://doi.org/10.1017/CB09780511549816.

Blakely, R. J., Brocher, T. M., \& Wells, R. E. 2005: Subduction-zone magnetic anomalies and implications for hydrated forearc mantle. Geology 33, 445-448.

Boschi, C., Früh-Green, G.L. \& Escartín, J. 2006: Occurrence and significance of serpentinite-hosted, talc-and amphibole-rich fault rocks in modern oceanic settings and ophiolite complexes: An overview. Ofioliti 31, 129-140. 
Bucher-Nurminen, K. 1991: Mantle fragments in the Scandinavian caledonides. Tectonophysics 190, 173-192. https://doi.org/10.1016/0040-1951(91)90429-V.

Clark, D.A. 1999: Magnetic petrology of igneous intrusions: implications for exploration and magnetic interpretation. Exploration Geophysics 30, 5-26. https://doi.org/10.1071/EG999005.

Coleman, R.G. \& Keith, T.E. 1971: A chemical study of serpentinization-Burro Mountain, California. Journal of Petrology 12, 311-328. https://doi.org/10.1093/petrology/12.2.311.

Daae, F., Økland, I., Dahle, H., Jørgensen, S., Thorseth, I. \& Pedersen, R. 2013: Microbial life associated with low-temperature alteration of ultramafic rocks in the Leka ophiolite complex. Geobiology 11, 318-339. https://doi.org/10.1111/gbi.12035.

deMartin, B., Sohn, R., Canales, J.P. \& Humphris S. 2007: Kinematics and geometry of active detachment faulting beneath the Trans-Atlantic Geotraverse (TAG) hydrothermal field on the Mid-Atlantic Ridge. Geology 35, 711-714. https://doi.org/10.1130/G23718A.1.

Dilek, Y. \& Furnes, H. 2014: Ophiolites and Their Origins. Elements 10, 93-100.

https://doi.org/10.2113/gselements.10.2.93.

Dunning, G. \& Pedersen, R. 1988: U/Pb ages of ophiolites and arc-related plutons of the Norwegian Caledonides: implications for the development of lapetus. Contributions to Mineralogy and Petrology 98, 13-23. https://doi.org/10.1007/BF00371904.

Evans, B.W., Hattori, K. \& Baronnet, A. 2013: Serpentinite: what, why, where?. Elements 9, 99-106. https://doi.org/10.2113/gselements.9.2.99.

Finlay, C.C., Maus, S., Beggan, C.D., Hamoudi, M., Lowes, F.J., Olsen, N. \& Thébault, E. 2010: Evaluation of candidate geomagnetic field models for IGRF-11. Earth, planets and space 62, 787-804.

https://doi.org/10.5047/eps.2010.11.005.

Früh-Green, G.L., Connolly, J.A., Plas, A., Kelley, D.S. \& Grobéty, B. 2004: Serpentinization of oceanic peridotites: implications for geochemical cycles and biological activity. The subseafloor biosphere at midocean ridges 144, 119-136. https://doi.org/10.1029/144GM08.

Furnes, H., Pedersen, R. \& Stillman, C. 1988: The Leka Opholite Complex, central Norwegian Caledonides: field characteristics and geotectonic significance. Journal of the Geological Society 145, 401-412. https://doi.org/10.1144/gsjgs.145.3.0401.

Haslwanter, T. 2016: Display of Statistical Data: In An Introduction to Statistics with Python, Springer, 51-71. https://doi.org/10.1007/978-3-319-28316-6.

Hintze, J.L. \& Nelson, R.D. 1998: Violin plots: a box plot-density trace synergism. The American Statistician 52, 181-184. https://doi.org/10.1080/00031305.1998.10480559.

Hinze, W.J., Von Frese, R.R. \& Saad, A.H. 2013: Gravity and magnetic exploration: Principles, practices, and applications. Cambridge University Press, 0521871018.

Huang, R., Lin, C.T., Sun, W., Ding, X., Zhan, W. \& Zhu, J. 2017: The production of iron oxide during peridotite serpentinization: Influence of pyroxene. Geoscience Frontiers 8, 1311-1321.

https://doi.org/10.1016/j.gsf.2017.01.001.

Iyer, K., Austrheim, H., John, T. \& Jamtveit, B. 2008: Serpentinization of the oceanic lithosphere and some geochemical consequences: constraints from the Leka Ophiolite Complex, Norway. Chemical Geology 249, 66-90. https://doi.org/10.1016/j.chemgeo.2007.12.005.

Journel, A.G. \& Huijbregts, C.J. 1978: Mining Geostatistics. Academic Press, London, 600 pp.

Komor, S.C., Elthon, D. \& Casey, J.F. 1985: Serpentinization of cumulate ultramafic rocks from the North Arm Mountain massif of the Bay of Islands ophiolite. Geochimica et Cosmochimica Acta 49, 2331-2338. https://doi.org/10.1016/0016-7037(85)90233-9.

Maaløe, S. 2005: The dunite bodies, websterite and orthopyroxenite dikes of the Leka ophiolite complex, Norway. Mineralogy and Petrology 85, 163-204. https://doi.org/10.1007/s00710-005-0085-5. 
Mackenzie, G.D., Maguire, P.K.H., Coogan, L.A., Khan, M.A., Eaton, M. \& Petrides, G. 2006: Geophysical constraints on the crustal architecture of the Troodos ophiolite: results from the IANGASS project. Geophysical Journal International 167, 1385-1401. https://doi.org/10.1111/j.1365-246X.2006.03144.x.

Maffione, M., Morris, A., Plümper, O. \& van Hinsbergen, D.J. 2014: Magnetic properties of variably serpentinized peridotites and their implication for the evolution of oceanic core complexes. Geochemistry, Geophysics, Geosystems 15, 923-944. https://doi.org/10.1002/2013GC004993.

Manatschal, G., Marquer, D. \& Früh-Green, G.L. 2000: Channelized fluid flow and mass transfer along a rift-related detachment fault (Eastern Alps, southeast Switzerland). Geological Society of America Bulletin 112, 21-33. https://doi.org/10.1130/0016-7606(2000)112<21:CFFAMT>2.0.CO;2.

McArthur, K.L., Frost, C.D., Barnes, C.G., Prestvik, T. \& Nordgulen, Ø. 2014: Tectonic reconstruction and sediment provenance of a far-travelled oceanic nappe, Helgeland Nappe Complex, west-central Norway. Geological Society, London, Special Publications 390, 583-602. https://doi.org/10.1144/SP390.3.

Michels, A.C., McEnroe, S.A. \& Fichler, C. 2018: Geophysical expression of the Leka Ophiolite, Norway, modeled from integrated gravity, magnetic and petrophysical data. Norwegian Journal of Geology 98 103-125. https://doi.org/10.17850/njg98-1-07.

Miller, H.G. \& Singh, V.J. 1994: Potential Field tilt - A new concept for location of potential field sources. Applied Geophysics 32, 213-217. https://doi.org/10.1016/0926-9851(94)90022-1.

Nuriel, P., Katzir, Y., Abelson, M., Valley, J.W., Matthews, A., Spicuzza, M.J. \& Ayalon, A. 2009: Faultrelated oceanic serpentinization in the Troodos ophiolite, Cyprus: Implications for a fossil oceanic core complex. Earth and Planetary Science Letters 282, 34-46.

https://doi.org/10.1016/j.epsl.2009.02.029.

O'Hanley, D.S. 1991: Fault-related phenomena associated with hydration and serpentine recrystallization during serpentinization. The Canadian Mineralogist 29, 21-35.

Okland, I., Huang, S., Dahle, H., Thorseth, I.H. \& Pedersen, R.B. 2012: Low temperature alteration of serpentinized ultramafic rock and implications for microbial life. Chemical Geology 318, 75-87. https://doi.org/10.1016/j.chemgeo.2012.05.015.

Olesen, O., Barnawal, V., Brönner, M., Dalsegg, E., Dumais, M.-A., Gellein, J., Gernigon, L., Heldal, T., Larsen, B.E., Lauritsen, T., Lutro, O., Maystrenko, Y., Nasuti, A., Roberts, D., Rueslåtten, H., Rønning, J.S., Slagstad, T., Solli, A. \& Stampolidis, A. 2015: Coop Phase 2 Crustal OnshoreOffshore Project. NGU Report 2015.063, 410 pp.

Pearce, J.A., Lippard, S. \& Roberts, S. 1984: Characteristics and tectonic significance of supra-subduction zone ophiolites. Geological Society, London, Special Publications 16, 77-94. https://doi.org/10.1144/GSL.SP.1984.016.01.06.

Pedersen, R. \& Furnes, H. 1991: Geology, magmatic affinity and geotectonic environment of some Caledonian ophiolites in Norway. Journal of Geodynamics 13, 183-203. https://doi.org/10.1016/0264-3707(91)90038-G.

Pedersen, R.B., Furnes, H., Prestvik, T., Barnes, C.G. \& Roberts, D. 2011: Leka, bedrock geology map 1725 IV, scale 1:50,000, Norges geologiske unders $\varnothing$ kelse.

Péron-Pinvidic, G. \& Manatschal G. 2009: The final rifting evolution at deep magma-poor passive margins from Iberia-Newfoundland: a new point of view. International Journal of Earth Sciences 98, 1581-1597. https://doi.org/10.1007/s00531-008-0337-9.

Prestvik, T. 1972: Alpine-type mafic and ultramafic rocks of Leka, Nord-Trøndelag. Norges Geologisk Undersøkelse 273, 23-34.

Prestvik, T. 1980: The Caledonian ophiolite complex of Leka, north central Norway. Paper presented at the Ophiolites. Proceedings of the International Ophiolite Symposium, Cyprus, pp. 555-566. 
Prestvik, T. 1985: Origin of the volcanic Storøya Group, Leka. Results from new geochemical investigations. Norsk geologisk tidsskrift 66, 237-239.

Prestvik, T. \& Roaldset, E. 1978: Rare earth element abundances in Caledonian metavolcanics from the island of Leka, Norway. Geochemical journal 12, 89-100.

https://doi.org/10.2343/geochemj.12.89.

Sindre, A. \& Pedersen, R.-B. 1990: Gravimetrisk undersokelse av Leka ofiolittkompleks. Norges geologiske undersøkelse Report 90.152, 20 pp.

Smith, D.K., Cann, J.R. \& Escartín, J. 2006: Widespread active detachment faulting and core complex formation near $13 \mathrm{~N}$ on the Mid-Atlantic Ridge. Nature 442, 440.

https://doi.org/10.1038/nature04950.

Titus, S., Fossen, H., Pedersen, R., Vigneresse, J. \& Tikoff, B. 2002: Pull-apart formation and strike-slip partitioning in an obliquely divergent setting, Leka Ophiolite, Norway. Tectonophysics 354, 101-119. https://doi.org/10.1016/S0040-1951(02)00293-7. 